Check for updates

Cite this: RSC Adv., 2018, 8, 39579

Received 15th September 2018 Accepted 13th November 2018

DOI: $10.1039 / c 8 r a 07683 a$

rsc.li/rsc-advances

\section{Bilayer graphene/HgCdTe based very long infrared photodetector with superior external quantum efficiency, responsivity, and detectivity $\dagger$}

\author{
Shonak Bansal, (D) a Kuldeep Sharma, ${ }^{a}$ Prince Jain, ${ }^{a}$ Neha Sardana, ${ }^{b}$ Sanjeev Kumar, ${ }^{c}$ \\ Neena Gupta a and Arun K. Singh (ID *a
}

\begin{abstract}
We present a high-performance bilayer graphene (BLG) and mercury cadmium telluride $\left(\mathrm{Hg}_{1-x} \mathrm{Cd}_{x=0.1867} \mathrm{Te}\right)$ heterojunction based very long wavelength infrared (VLWIR) conductive photodetector. The unique absorption properties of graphene enable a long carrier lifetime of charge carriers contributing to the carrier-multiplication due to impact ionization and, hence, large photocurrent and high quantum efficiency. The proposed $\mathrm{p}^{+}-\mathrm{BLG} / \mathrm{n}-\mathrm{Hg}_{0.8133} \mathrm{Cd}_{0.1867}$ Te photodetector is characterized and analyzed in terms of different electrical and optical characteristic parameters using computer simulations. The obtained results are further validated by developing an analytical model based on drift-diffusion, tunneling and Chu's methods. The photodetector has demonstrated a superior performance including improved dark current density $\left(\sim 1.75 \times 10^{-14} \mu \mathrm{A} \mathrm{cm}{ }^{-2}\right)$, photocurrent density $\left(\sim 8.33 \mu \mathrm{A} \mathrm{cm}^{-2}\right)$, internal quantum efficiency $\left(Q E_{\text {int }} \sim 99.49 \%\right)$, external quantum efficiency $\left(Q E_{\text {ext }} \sim\right.$ $89 \%)$, internal photocurrent responsivity $\left(\sim 13.26 \mathrm{~A} \mathrm{~W}^{-1}\right)$, external photocurrent responsivity $\left(\sim 9.1 \mathrm{~A} \mathrm{~W}^{-1}\right)$, noise equivalent power $\left(\sim 8.3 \times 10^{-18} \mathrm{~W}\right)$, total noise current $(\sim 1.06 \mathrm{fA})$, signal to noise ratio $(\sim 156.18$ $\mathrm{dB}), 3 \mathrm{~dB}$ cut-off frequency $(\sim 36.16 \mathrm{GHz})$, and response time of $9.4 \mathrm{ps}$ at $77 \mathrm{~K}$. Furthermore, the effects of different external biasing, light power intensity, and temperature are evaluated, suggesting a high $\mathrm{QE}_{\text {ext }}$ of $3337.70 \%$ with a bias of $-0.5 \mathrm{~V}$ near room temperature.
\end{abstract}

\section{Introduction}

Infrared (IR) photodetectors have been successfully demonstrated from a wide variety of narrow bandgap semiconductors (Si and $\mathrm{Ge})^{1-3}$ and alloys including III-V $\left(\operatorname{InAs}_{1-x} \mathrm{Sb}_{x}\right.$, InAs, GaAs $),{ }^{4-6}$ IV-VI $\left(\mathrm{Pb}_{1-x} \mathrm{Sn}_{x} \mathrm{Te}\right),{ }^{4}$ II-VI $\left(\mathrm{Hg}_{1-x} \mathrm{Cd}_{x} \mathrm{Te}, \mathrm{CdZnTe}\right.$, CdSeTe). ${ }^{4,7-10}$ These materials absorb the incident photon energy corresponding to their bandgaps and result in the output photocurrent. ${ }^{11}$ InSb, a III-V compound semiconductor material was first used for IR detection. The IR detection region is categorized into short wavelength IR (SWIR: 1-3 $\mu \mathrm{m}$ ), mid wavelength IR (MWIR: 3-5 $\mu \mathrm{m}$ ), long wavelength IR (LWIR: 8-14 $\mu \mathrm{m})$ and very long wavelength IR (VLWIR: $14-30 \mu \mathrm{m}$ ) ranges. ${ }^{12}$ The potential applications of IR photodetectors include biomedical and thermal imaging, gas sensing, night vision, spectroscopy, and free space communication etc. ${ }^{\mathbf{4 1 3 - 1 5}}$ Rapid

${ }^{a}$ Department of Electronics and Communication Engineering, Punjab Engineering College (Deemed to be University), Sector-12, Chandigarh-160012, India. E-mail: arun@pec.ac.in

${ }^{b}$ Department of Metallurgical and Materials Engineering, Indian Institute of Technology, Ropar, India

'Department of Applied Sciences, Punjab Engineering College (Deemed to be University), Sector-12, Chandigarh-160012, India

† Electronic supplementary information (ESI) available. See DOI: 10.1039/c8ra07683a advances are being made in developing inexpensive narrow bandgap semiconductor photodetectors with improved sensitivity and longer wavelengths. As a result, low dimensional structures, including quantum-well, quantum-dot, and quantum-wire, based IR photodetectors are reported with improved performances, but with expensive fabrication processes. ${ }^{16-19}$ On the other hand, the low leakage current, tunable bandgap, better stability, low thermal generation rate and relatively high absorption coefficient make the ternary alloy mercury cadmium telluride (MCT: $\mathrm{Hg}_{1-x} \mathrm{Cd}_{x} \mathrm{Te}$ ) a suitable material for high performance IR detectors. ${ }^{12,14,20-22}$ So far, numerous $\mathrm{Hg}_{1-x} \mathrm{Cd}_{x}$ Te-based IR photodetectors with different configurations such as $\mathrm{p}-\mathrm{n},{ }^{23,24} \mathrm{p}-\mathrm{i}-\mathrm{n},{ }^{\mathbf{1 4 , 2 5}}$ dual band IR detector, ${ }^{15,26}$ and avalanche photodiode ${ }^{27}$ have been reported at cryogenic temperatures. The high dark current limited by Auger recombination processes and low temperature operations are the major disadvantage of MCT based IR photodetector. ${ }^{\mathbf{1 4 , 2 0 , 2 8 , 2 9}}$ Hence, there is a requirement to design and develop MCT based IR photodetectors demonstrating higher efficiencies near room temperature.

The excellent electrical and optical properties of graphene (Gr) enables utilisation of $\mathrm{Gr}$ as a transparent electrode integrated with conventional photodetectors for ultraviolet (UV) to IR regions. ${ }^{30}$ The Gr/semiconductor heterojunction based photodetectors are expected to demonstrate a low dark current, 
low power dissipation, small parasitics, higher breakdown voltage, and high response speed than that of conventional homostructures. The Gr has been successfully composited with different materials like $\mathrm{ZnO},{ }^{31,32} \mathrm{Si}^{33}{ }^{33} \mathrm{CdS}^{34}$ (for UV applications), $\mathrm{CdSe}^{35} \mathrm{GaN}^{36}$ (for visible applications), and $\mathrm{Si}^{1,37} \mathrm{Ge},{ }^{3} \mathrm{PbS},{ }^{38}$ $\mathrm{GaAs}^{39}$ (for IR applications). However, the zero bandgap and small optical absorption ( $2.3 \%$ ) of monolayer graphene (MLG) result in limited photocurrent responsivity $\left(<1 \mathrm{~A} \mathrm{~W}^{-1}\right)$ and photocurrent $\left(I_{\text {light }}\right)$ to dark current $\left(I_{\text {dark }}\right)$ ratios $\left(I_{\text {light }}\right)$ $\left.I_{\text {dark }}\right) .{ }^{6,30,33,40-42}$ Accordingly, several efforts including utilisation of few layer graphene, Gr quantum dots, inducing small bandgap in Gr layers using either doping or under transverse electric fields are made to improve the charge injection and separation, suppressing dark current with improved efficiency. ${ }^{\mathbf{1 1}, \mathbf{1 3 , 4 3 - 4 6}}$ The intentional doping in monolayer and bilayer Gr shifts the Fermi-level either upward or downward, creating a bandgap opening. ${ }^{47}$ To the best of our knowledge, a maximum bandgap of $430 \mathrm{meV}$ is found in p-doped bilayer graphene (BLG). ${ }^{48} \mathrm{Xu}$ et $a .^{49}$ demonstrated 25 times higher electrical conductance and optical transmittance of $80 \%$ from few layer (5-10) graphene transferred onto MCT substrate in the MWIR spectral region at 77 and $300 \mathrm{~K}$. Despite such studies, no photodetector combining BLG with MCT is successfully studied yet. Hence, here we propose and simulate a BLG/MCT based photodetector providing excellent light absorption and electron transport. The device exhibits a low dark current and high temperature operation due to lower thermo-generation rate. In this work, we investigate the effect of different external bias, incident light power intensity and temperature on the performance of proposed heterojunction photodetector. It is evident from the results that high external quantum efficiency $\left(\mathrm{QE}_{\text {ext }}\right)$ $(>100 \%)$ is achieved due to long lifetime of photo-induced hot carriers in the VLWIR spectral region. The obtained results are further validated by developing an empirical model based on drift-diffusion, tunneling and Chu's methods in VLWIR, suggesting potential applications in next-generation highperformance, ultra-low-power, and cost-effective IR photodetectors for optoelectronics devices.

\section{Device structure and description}

The inset of Fig. 1a shows the schematic of proposed BLG composite $\mathrm{Hg}_{1-x} \mathrm{Cd}_{x=0.1867} \mathrm{Te}$ based VLWIR photodetector. The highly doped $\mathrm{p}^{+}$-type BLG conformably cover $10.0 \mu \mathrm{m}$ wide lightly doped n-type $\mathrm{Hg}_{0.8133} \mathrm{Cd}_{0.1867}$ Te to form a heterojunction photodetector. The $\mathrm{p}^{+}$-doping of the $\mathrm{Gr}$ is typically being achieved through the chemical doping with $\mathrm{HNO}_{3},{ }^{50,51} \mathrm{FeCl}_{3},{ }^{52}$ $\mathrm{AuCl}_{3}{ }^{53,54} \mathrm{SOCl}_{2},{ }^{55,56}$ and $\mathrm{NbCl}_{5}$ (ref. 57) utilising chemical vapor deposition (CVD) technique. Practically, the Gr layers can be directly mechanically exfoliated or be transferred to suitable substrate utilizing $\mathrm{Cu}$ films in CVD growth techniques without any contamination issues. ${ }^{58}$ The electrical ohmic contacts of aluminium $(\mathrm{Al})$ are made as anode and cathode to collect the photo-generated charge carriers. The nominal thickness of

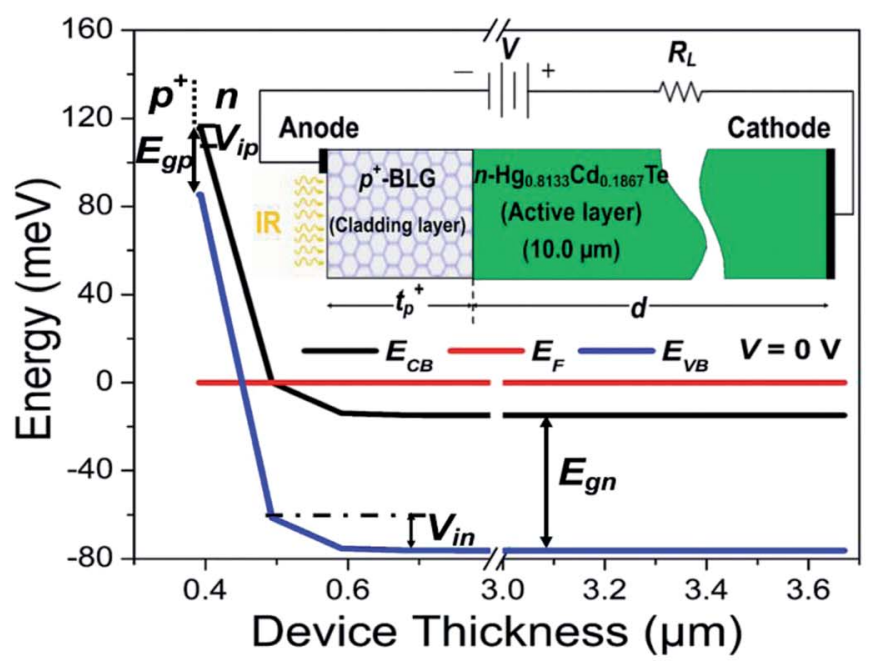

(a)

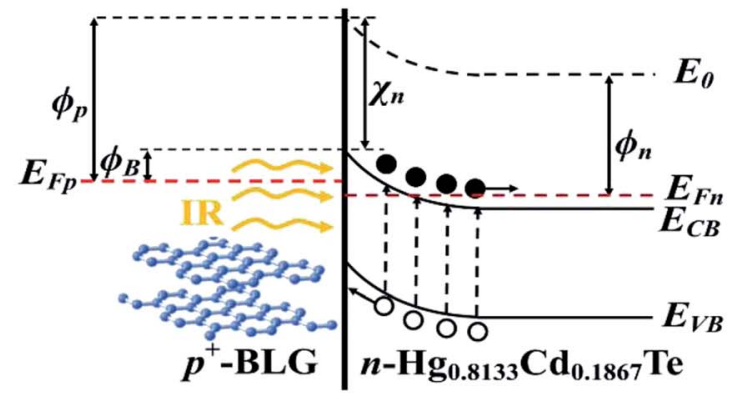

(b)

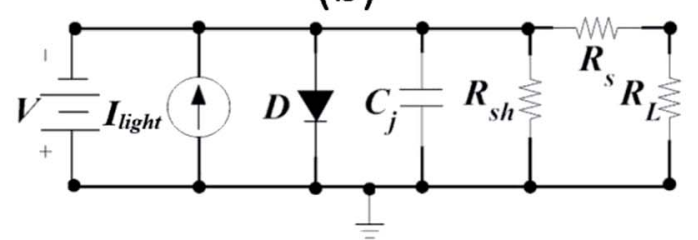

(c)

Fig. 1 (a) The simulated energy bandgap diagram of $\mathrm{p}^{+}-\mathrm{BLG} / \mathrm{n}-\mathrm{Hg}_{0.8133} \mathrm{Cd}_{0.1867} T$ e VLWIR photodetector at zero-bias $(V=0 \mathrm{~V})$ under no illumination conditions. Here, $E_{\mathrm{CB}}$ and $E_{\mathrm{VB}}$ represent conduction and valence band energies, respectively; $E_{\mathrm{F}}$ is Fermi-level energy; $E_{\mathrm{gp}}$ and $E_{\mathrm{gn}}$ are the bandgap of $\mathrm{p}^{+}$- and n-regions, respectively; $V_{\mathrm{ip}}$ and $V_{\text {in }}$ are the potential barriers in $\mathrm{p}^{+}$- and $\mathrm{n}$-regions, respectively. The schematic of proposed photodetector is shown in the inset. The VLWIR radiations with an illumination cut-off wavelength of $20.6 \mu \mathrm{m}$ are incident on the $\mathrm{p}^{+}-$ $\mathrm{BLG}$. Here, $t_{\mathrm{p}^{+}}$and $d$ are the thickness of $\mathrm{p}^{+}$- and $\mathrm{n}$-regions, respectively. $V$ and $R_{\mathrm{L}}$ represent the applied bias and load resistance, respectively. (b) The schematic energy bandgap diagram of proposed photodetector under illumination and reverse bias condition. Here, $E_{0}$ is the vacuum energy level; $E_{\mathrm{Fp}}$ and $E_{\mathrm{Fn}}$ are Fermi-level energies of $\mathrm{p}^{+}$- and $\mathrm{n}$-regions, respectively; $\phi_{\mathrm{B}}$ is the barrier height and $\chi_{\mathrm{n}}$ is the electron affinity of the $\mathrm{n}$ region. $\phi_{\mathrm{p}}$ and $\phi_{\mathrm{n}}$ denote the work function of $\mathrm{p}^{+}$- and $\mathrm{n}$-regions, respectively. Under illumination the photo-induced carriers accumulate in the potential well, raising the Fermi-level and increasing the conductivity of the device. (c) The equivalent circuit of proposed BLG/MCT photodetector indicating photocurrent $\left(l_{\text {light }}\right)$, junction capacitance $\left(C_{\mathrm{j}}\right)$, shunt resistance $\left(R_{\mathrm{sh}}\right)$ and series resistance $\left(R_{\mathrm{s}}\right)$ is utilised for evaluating dark current properties in Silvaco Mixed-Mode circuit simulations. 
$2 \mathrm{~nm}$ for BLG is considered for our studies which is in consonance with previously reported values. ${ }^{59-61}$ The proposed $\mathrm{p}^{+}$$\mathrm{BLG} / \mathrm{n}-\mathrm{Hg}_{0.8133} \mathrm{Cd}_{0.1867} \mathrm{Te}$ photodetector can be grown on lattice matched CdZnTe substrate. CdZnTe substrate is chosen because MCT/CdZnTe interface offers less interface trap charge as compared to $\mathrm{Si}, \mathrm{Ge}$, and CdTe substrates. ${ }^{24}$ In this paper, we have not considered the substrate effect, as it does not affect the device performance significantly. The Silvaco Atlas software is utilised to design and evaluate the electrical and optical performances of BLG/HgCdTe photodetector. The VLWIR radiations are incident from the $\mathrm{p}^{+}$-BLG cladding window over the narrow bandgap $\mathrm{n}-\mathrm{Hg}_{0.8133} \mathrm{Cd}_{0.1867} \mathrm{Te}$ active/absorbing layer. The $\mathrm{p}^{+}$-BLG is used as a light absorber. The lightly doped n$\mathrm{Hg}_{0.8133} \mathrm{Cd}_{0.1867} \mathrm{Te}$ generates total dark current and photocurrent. The bandgap and doping concentration of active region are selected to give better absorption of VLWIR radiations suppressing thermally generated carriers. In order to simulate the device, a bandgap of $250 \mathrm{meV}$ for BLG is considered. ${ }^{62,63}$ When VLWIR light illuminates the $\mathrm{p}^{+}-\mathrm{BLG} / \mathrm{n}-\mathrm{Hg}_{0.8133} \mathrm{Cd}_{0.1867} \mathrm{Te}$ heterojunction, the hot photo-carriers transport from the active layer to the $\mathrm{Gr}$ layer due to built-in electric field $\left(E_{\text {built-in }}\right){ }^{64} \mathrm{As}$ a result, the change in graphene conduction is observed according to the relation, $\Delta \sigma=\Delta n q \mu,{ }^{65,66}$ where $\Delta n$ represents variation in carrier-concentration of graphene; $q$ corresponds to the electronic charge; and $\mu$ is the carrier mobility. The schematic illustration of depletion region with a barrier height $\left(\phi_{\mathrm{B}}\right)$ between the BLG and HgCdTe is given in Fig. 1b. The presence of potential barrier within the heterojunction is due to the existence of gradients in electron affinity $\nabla \chi$ and electrostatic potential $\nabla V$. The electrons are dominated charge carriers than holes. The electrons travel from n-region into the lower energy states in $\mathrm{p}^{+}$-region, leaving the positively charged empty states in the n-region. Accordingly, the energy band bends upward in the vicinity of the $\mathrm{p}^{+}-\mathrm{n}$ heterojunction to form an $E_{\text {built-in }}$. The doping profile of the material determines the barrier height, however, potential variation results in energy band drop at $\mathrm{p}^{+}-\mathrm{n}$ interface junction ${ }^{23}$ as shown in Fig. 1a and b. The existence of the small bandgap in $\mathrm{Gr}$ due to doping will change the work function of Gr resulting in shifting of Fermi-level towards the conduction band. This makes graphene different than the others 2D semiconductor materials. ${ }^{67}$ It is also observed from Fig. 1b that under illumination, the photo-induced carriers accumulate in the potential well, raising the Fermi-level and increasing the conductivity of the device. The energy band diagram of the device can be explained by the classical theory of Anderson. ${ }^{68}$ The absorbed photo carriers undergo hot carrier multiplication (CM) by impact ionization (also known as inverse Auger recombination process) ${ }^{69-72}$ in $\mathrm{p}^{+}-\mathrm{BLG}$, subsequently cross the barrier through internal photoemission (IPE) process (in picosecond scale), ${ }^{33}$ and finally be collected by $\mathrm{n}-\mathrm{Hg}_{0.8133^{-}}$ $\mathrm{Cd}_{0.1867} \mathrm{Te}$ contributing the total photocurrent. The carrier multiplication factor can further be tuned with chemical doping. ${ }^{73,74}$ The fast recombination rate (in picosecond) of the photogenerated carriers results in a maximum multiplication factor of 4.3 by the impact ionization process. ${ }^{75}$ Thus carrier multiplication, i.e. internal gain mechanism in BLG will enhance the photocurrent $I_{\text {light }}$ of the device due to the increase in carriers. ${ }^{76}$ The increase in photocurrent will result in higher internal quantum efficiency $\left(\mathrm{QE}_{\text {int }}\right),{ }^{33}$ facilitates to break through the upper-limit of traditional MCT based IR photodetectors. This indicate that our BLG composite photodetectors can still work effectively under a low illumination conditions. In our device, we have achieved a carrier multiplication factor of 1.25 for $\mathrm{p}^{+}$-doped graphene at $250 \mathrm{~K}$, which is in good agreement to the earlier reported values. ${ }^{73,74}$ In addition, an equivalent Mixed-Mode circuit is utilised for estimating device performances in dark condition as shown in Fig. 1c. It consists of an equivalent diode in parallel with shunt resistance $R_{\mathrm{sh}}$, junction capacitance $C_{\mathrm{j}}$, and load resistance $R_{\mathrm{L}}$ with series resistance $R_{\mathrm{S}}$ at an applied bias $V$ for generating carriers contributing to the device current. The effect of illumination is implemented by a constant current source $I_{\text {light }}$ in Silvaco Mixed-Mode simulator.

In self-powered mode, the depletion layer width $w=$ $\left[2 \varepsilon_{0} \varepsilon_{\mathrm{r} 1} \varepsilon_{\mathrm{r} 2}\left(V_{\mathrm{bi}}-V\right)\left(N_{\mathrm{A}}^{2}+N_{\mathrm{D}}^{2}\right) /\left(q\left(\varepsilon_{\mathrm{r} 1} N_{\mathrm{A}}+\varepsilon_{\mathrm{r} 2} N_{\mathrm{D}}\right) N_{\mathrm{A}} N_{\mathrm{D}}\right)\right]^{1 / 2}$ of the heterojunction is found to be $64.28 \mathrm{~nm}$ for a built-in potential $\left(V_{\mathrm{bi}}=V_{\mathrm{ip}}+V_{\mathrm{in}}\right)$ of $21 \mathrm{mV}$. Here, $V_{\mathrm{ip}}$ and $V_{\mathrm{in}}$ are the barriers corresponding to energy band bending at $\mathrm{p}^{+}$- and $\mathrm{n}$-regions, respectively. $\varepsilon_{0}$ is the absolute permittivity and $\varepsilon_{\mathrm{r} 1} \& \varepsilon_{\mathrm{r} 2}$ represent the relative permittivity in $\mathrm{p}^{+}$- and $\mathrm{n}$-regions, respectively. $N_{\mathrm{A}}\left(2 \times 10^{22} \mathrm{~cm}^{-3}\right)$ and $N_{\mathrm{D}}\left(1 \times 10^{16} \mathrm{~cm}^{-3}\right)$ corresponds to the acceptor and donor doping concentrations in $\mathrm{p}^{+}$- and n-regions, respectively. The thickness of bilayer graphene is considered to be $2.0 \mathrm{~nm}$, which is considerably smaller than that of MCT $(10.0 \mu \mathrm{m})$. Accordingly, the depletion region extends inside the MCT (n-side) resulting in gradual shrinkage in band diagram towards BLG/MCT interface as observed in Fig. 1a employing computer simulations. The junction capacitance $C_{\mathrm{j}}=\varepsilon_{0} \varepsilon_{\mathrm{r} 2} A / w$ in self-powered mode is found to be $0.98 \mathrm{fF}$. The device exhibits the transit time $\tau_{t_{\mathrm{r}}}=w / v_{\mathrm{satn}}$ of $6.4 \mathrm{ps}$, where $v_{\text {satn }}$ is the carrier saturation velocity $\left(10^{6} \mathrm{~cm} \mathrm{~s}^{-1}\right)$ in $\mathrm{n}$-region. The dependence of $\varepsilon_{\mathrm{r} 2}$ on $x$ composition for n-region is approximated by: ${ }^{12}$

$$
\varepsilon_{\mathrm{r} 2}(x)=20.5-15.6 x+5.7 x^{2}
$$

\section{Results and discussions}

\section{Electrical characterization}

The $\mathrm{p}^{+}-\mathrm{BLG} / \mathrm{n}-\mathrm{Hg}_{0.8133} \mathrm{Cd}_{0.1867} \mathrm{Te}$ photodetector is electrically characterized by solving continuity, carrier transport and Poisson equations with optimized boundary conditions as approximated by Boltzmann's transport model. ${ }^{15}$ Here, BLG is considered as 3D in nature analogous to earlier reported studies demonstrating the integration of multilayer graphene with other conventional semiconductors which couples 2D transport equations to $3 \mathrm{D}$ equations. ${ }^{67} \mathrm{~A} 2 \mathrm{D}$ semiconductor material has one physical dimension of the order of Fermi wavelength $\lambda_{F}$. In our case, $\lambda_{\mathrm{F}}(\mathrm{nm})=2 \times 10^{7} \sqrt{\frac{\pi}{n}}$ of graphene is estimated to be around $0.56 \mathrm{~nm}$ for the sheet carrier density $(n)$ of $4 \times 10^{15}$ $\mathrm{cm}^{-2}$. The obtained value of $\lambda_{F}$ is smaller than the considered thickness of doped BLG ( $2 \mathrm{~nm})$, hence, it is necessary to 
consider 3D equations for estimating device characteristics. Further, to reproduce the carrier transport in graphene a driftdiffusion approach is implemented to degenerate semiconductor and parabolic shape of the conduction band. ${ }^{77}$ The Newton-Richardson iteration method and concentration dependent Analytic model are used to estimate the carrier mobility in the photodetector. ${ }^{\mathbf{1 5 , 2 4}}$ In order to characterize the carrier lifetime and the dark current in the proposed photodetector, Shockley-Read-Hall (SRH), Auger, optical (band-toband), trap assisted tunneling (TAT), and band-to-band (BTB) standard tunneling mechanism models are considered. The doping and carrier densities are evaluated using Fermi-Dirac statistics. ${ }^{\mathbf{1 5 , 2 4 , 7 8}}$

The performance of the photodetector at $77 \mathrm{~K}$ is evaluated analytically for the operation at the wavelength of $20.6 \mu \mathrm{m}$. The photons having energy greater than the bandgap create electron-hole pairs in the lightly doped n-region. The mole fraction $x$ of cadmium in the $\mathrm{Hg}_{1-x} \mathrm{Cd}_{x}$ Te tunes the energy bandgap in VLWIR with a cut-off wavelength of $20.6 \mu \mathrm{m}$. For $\mathrm{n}-\mathrm{Hg}_{1-x} \mathrm{Cd}_{x} \mathrm{Te}$, the energy bandgap $\left(E_{\text {gn }}\right)$, electron affinity $\left(\chi_{\mathrm{n}}\right)$, and intrinsic carrier concentration $\left(n_{\mathrm{in}}\right)$ as a function of $x$ composition and lattice temperature $T$ are approximated by eqn (2), (3) and (4), respectively. ${ }^{12,24,79}$

$$
\begin{aligned}
E_{\mathrm{gn}}(x, T)= & -0.302+1.93 x-0.810 x^{2}+0.832 x^{3}+5.35 \\
& \times 10^{-4}(1-2 x) \times\left(\frac{T^{3}-1822}{T^{2}+255.2}\right) \\
\chi_{\mathrm{n}}(x, T)= & 4.23-0.813 \times\left[E_{\mathrm{g}}(x, T)-0.083\right] \\
n_{\mathrm{in}}(x, T)= & \left(5.24256-3.57290 x-4.74019 \times 10^{-4} T+1.25942\right. \\
& \left.\times 10^{-2} x T-5.77046 x^{2}-4.24123 \times 10^{-6} T^{2}\right) \\
& \times 10^{14} E_{\mathrm{gn}}(x, T)^{0.75} T^{1.5} \mathrm{e}^{\left(\frac{-q E_{\mathrm{gn}}(x, T)}{2 k T}\right)}
\end{aligned}
$$

where, $k$ is the Boltzmann constant.

The electron effective mass $\left(m_{\mathrm{n}}^{*}\right)$ of $\mathrm{n}-\mathrm{Hg}_{1-x} \mathrm{Cd}_{x} \mathrm{Te}$ material is estimated by using Weiler's expression ${ }^{\mathbf{8 0}}$ (eqn S1 and S2 $\dagger$ ). The various computation parameters based on previous studies

\begin{tabular}{|c|c|c|}
\hline Parameters & $\mathrm{p}^{+}-\mathrm{BLG}$ & $\mathrm{n}-\mathrm{Hg}_{1-x} \mathrm{Cd}_{x} \mathrm{Te}$ \\
\hline$x$ Composition & - & 0.1867 (cal. $)^{24}$ \\
\hline Bandgap (meV) & $(250)^{67,81}$ & $60.2\left(\right.$ cal. $^{24}$ \\
\hline Affinity $(\chi)(e V)$ & $(4.2)^{67,81}$ & $4.25{\text { (cal. })^{24,79}}^{2}$ \\
\hline Relative permittivity $\left(\varepsilon_{\mathrm{r}}\right)$ & $(3.3)^{67,81}$ & 17.8 (cal. $)^{12,24}$ \\
\hline$N_{\mathrm{CB}}\left(\mathrm{cm}^{-3}\right)$ & $\left(5.2 \times 10^{16}\right)^{67,81}$ & $1.0285 \times 10^{15}(\mathrm{cal} .)^{79}$ \\
\hline$N_{\mathrm{VB}}\left(\mathrm{cm}^{-3}\right)$ & $\left(5.2 \times 10^{16}\right)^{67,81}$ & $1.3310 \times 10^{18}(\mathrm{cal} .)^{79}$ \\
\hline$n_{\mathrm{i}}\left(\mathrm{cm}^{-3}\right)$ & $3.4312 \times 10^{8}(\mathrm{cal} .)^{79}$ & $3.8213 \times 10^{14}{\text { (cal. })^{24}}^{24}$ \\
\hline$N_{\mathrm{A}}\left(\mathrm{cm}^{-3}\right)$ & $2 \times 10^{22}$ (assumed $)$ & - \\
\hline$N_{\mathrm{D}}\left(\mathrm{cm}^{-3}\right)$ & - & $1 \times 10^{16}$ (assumed) \\
\hline
\end{tabular}
including effective density of states for electrons $\left(N_{\mathrm{CB}}\right)$ and holes $\left(N_{\mathrm{VB}}\right)$ in conduction and valence bands, respectively, intrinsic carrier concentration $\left(n_{\mathrm{i}}\right)$, and carrier (electron and hole) lifetimes are listed in Table $1 .^{\mathbf{1 2 , 2 4 , 6 7 , 8 1}}$ Fig. 2 shows the triangular

Table 1 Optimised simulation parameters used for device analysis

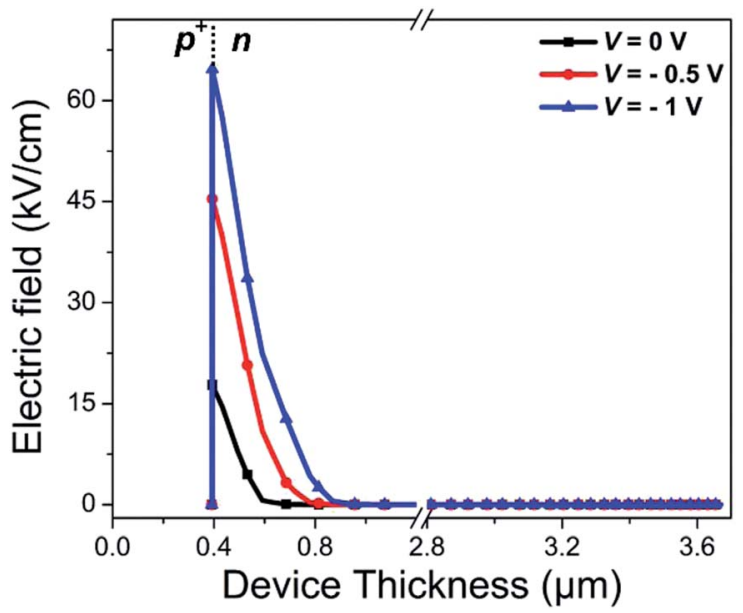

Fig. 2 The electric field profile across the device at different external biasing conditions demonstrate high electric field at the $\mathrm{p}^{+}-\mathrm{n}$ heterojunction of BLG and MCT.

shape built-in electric field profile across $\mathrm{p}^{+}-\mathrm{n}$ heterojunction VLWIR photodetector for different biasing conditions. The maximum value of electric field $\left(E_{\max }\right)$ is found to be 17.8, 45.4, and $64.6 \mathrm{kV} \mathrm{cm}^{-1}$ at the heterojunction of the device with an external bias of $0,-0.5$, and $-1 \mathrm{~V}$, respectively. The electric field $E(x)$ across the device can be written as:

$$
E(x)=\left\{\begin{array}{l}
-\frac{q N_{\mathrm{A}}}{\varepsilon_{0} \varepsilon_{\mathrm{r} 1}}\left(x_{\mathrm{p}^{+}}+x\right), \quad x_{\mathrm{p}^{+}} \leq x<0 \\
\frac{q N_{\mathrm{D}}}{\varepsilon_{0} \varepsilon_{\mathrm{r} 2}}\left(x_{\mathrm{n}}-x\right), \quad 0<x \leq x_{\mathrm{n}}
\end{array}\right.
$$

where $x_{\mathrm{p}^{+}}$and $x_{\mathrm{n}}$ are the depletion width in $\mathrm{p}^{+}$- and n-regions, respectively.

BLG is atomically thin with a thickness of the order of nm. This may create the depletion region width $x_{\mathrm{p}^{+}}$either almost fully depleted or very thin $\left(\approx 3.21 \times 10^{-16} \mathrm{~m}\right.$ in our case), hence, can be safely neglected. The electron-hole pairs from MCT can be effectively separated by high built-in $E_{\text {built-in }}$ to generate the photocurrent. The dark current density $\left(J_{\text {dark }}\right)$ is a combination of diffusion current density $\left(J_{\text {DIFF }}\right)$ in the neutral $\mathrm{p}^{+}$- and n-regions, drift current density $\left(J_{\mathrm{GR}}\right)$ due to generation-recombination of charge carriers in the depletion region and the tunneling current density $\left(J_{\text {TUN }}\right)$. $J_{\text {TUN }}$ consists of the contribution of both the trap-assisted tunneling (TAT) and band-to-band (BTB) tunneling. Accordingly, the total dark current density as a function of voltage and ambient temperature is given by:

$$
J_{\mathrm{dark}}(V, T)=J_{\mathrm{DIFF}}+J_{\mathrm{GR}}+J_{\mathrm{TAT}}+J_{\mathrm{BTB}}
$$

The total diffusion current density is evaluated as: ${ }^{24}$

$$
J_{\mathrm{DIFF}}=\left[\left(J_{\mathrm{p}}\right)_{\mathrm{n}}+\left(J_{\mathrm{n}}\right)_{\mathrm{p}}\right]\left(\mathrm{e}^{(q V / k T)}-1\right)
$$

where $V$ represents the applied bias voltage, the diffusion component of current density for holes $\left(J_{\mathrm{p}}\right)_{\mathrm{n}}$ and electrons $\left(J_{\mathrm{n}}\right)_{\mathrm{p}}$ in $\mathrm{n}$ - and $\mathrm{p}^{+}$-regions, respectively, are given as: 


$$
\begin{aligned}
\left(J_{\mathrm{p}}\right)_{\mathrm{n}}= & \frac{q n_{\mathrm{in}}^{2}}{N_{\mathrm{D}}} \sqrt{\frac{\mu_{\mathrm{p}} k T}{q \tau_{\mathrm{p}}}} \frac{\gamma_{\mathrm{p}} \cosh \left(\frac{d-x_{\mathrm{n}}}{L_{\mathrm{p}}}\right)+\sinh \left(\frac{d-x_{\mathrm{n}}}{L_{\mathrm{p}}}\right)}{\cosh \left(\frac{d-x_{\mathrm{n}}}{L_{\mathrm{p}}}\right)+\gamma_{\mathrm{p}} \sinh \left(\frac{d-x_{\mathrm{n}}}{L_{\mathrm{p}}}\right)} \\
& \times \mathrm{e}^{\left(-\frac{q\left(V_{\mathrm{bi}}+\Delta E_{\mathrm{v}}\right)}{k T}\right)} \\
\left(J_{\mathrm{n}}\right)_{\mathrm{p}}= & \frac{q n_{\mathrm{ip}}{ }^{2}}{N_{\mathrm{A}}} \sqrt{\frac{\mu_{\mathrm{n}} k T}{q \tau_{\mathrm{n}}}} \frac{\gamma_{\mathrm{n}} \cosh \left(\frac{t_{\mathrm{p}^{+}}-x_{\mathrm{p}^{+}}}{L_{\mathrm{n}}}\right)+\sinh \left(\frac{t_{\mathrm{p}^{+}}-x_{\mathrm{p}^{+}}}{L_{\mathrm{n}}}\right)}{\cosh \left(\frac{t_{\mathrm{p}^{+}}-x_{\mathrm{p}^{+}}}{L_{\mathrm{n}}}\right)+\gamma_{\mathrm{n}} \sinh \left(\frac{t_{\mathrm{p}^{+}}-x_{\mathrm{p}^{+}}}{L_{\mathrm{n}}}\right)} \\
& \times \mathrm{e}^{\left(-\frac{q\left(V_{\mathrm{bi}}+\Delta E_{\mathrm{CB}}\right)}{k T}\right)}
\end{aligned}
$$

where $n_{\text {in }}$ and $n_{\text {ip }}$ are the intrinsic carrier concentrations in $\mathrm{n}$ and $\mathrm{p}^{+}$-regions, respectively. $\mu_{\mathrm{p}}$ and $\mu_{\mathrm{n}}$ are the hole and electron mobilities, respectively. $\tau_{\mathrm{p}}$ and $\tau_{\mathrm{n}}$ represent the hole and electron lifetimes, respectively. $\gamma_{\mathrm{p}}=S_{\mathrm{p}} L_{\mathrm{p}} / D_{\mathrm{p}}$ and $\gamma_{\mathrm{n}}=$ $S_{\mathrm{n}} L_{\mathrm{n}} / D_{\mathrm{n}}$ are the ratios of surface to bulk recombination velocities in $\mathrm{p}^{+}$- and n-regions, respectively. Here, $S_{\mathrm{p}}=10^{3} \mathrm{~cm}$ $\mathrm{s}^{-1}$ and $S_{\mathrm{n}}=10^{5} \mathrm{~cm} \mathrm{~s}^{-1}$ are the surface recombination velocities of holes and electrons, respectively at the heterojunction. ${ }^{24} L_{\mathrm{p}}=\sqrt{D_{\mathrm{p}} \tau_{\mathrm{p}}}$ and $L_{\mathrm{n}}=\sqrt{D_{\mathrm{n}} \tau_{\mathrm{n}}}$ are the diffusion lengths of holes and electrons. $D_{\mathrm{p}}=\mu_{\mathrm{p}} k T / q$ and $D_{\mathrm{n}}=\mu_{\mathrm{n}} k T / q$ represent the diffusion coefficients of holes and electrons, respectively. The valence and conduction band-edge discontinuities, after the formation of the $\mathrm{p}^{+}-\mathrm{n}$ heterojunction are given by $\Delta E_{\mathrm{VB}}\left(=\Delta E_{\mathrm{g}}-\Delta E_{\mathrm{CB}}\right)$ and $\Delta E_{\mathrm{CB}}\left(=\chi_{\mathrm{n}}-\chi_{\mathrm{p}}\right) \cdot \chi_{\mathrm{n}}$ and $\chi_{\mathrm{p}}$ are the electron affinities of the wide and narrow bandgap materials, where $\chi_{\mathrm{n}}>\chi_{\mathrm{p}} . \Delta E_{\mathrm{g}}\left(=E_{\mathrm{gp}}-E_{\mathrm{gn}}\right)$ is total bandgap discontinuity and $E_{\mathrm{gp}}$ and $E_{\mathrm{gn}}$ represent the energy bandgaps in the $\mathrm{p}^{+}$- and n-regions.

The transfer of charge carriers across the $\mathrm{p}^{+}-\mathrm{n}$ heterojunction is strongly affected by the trap levels at the heterojunction particularly in depletion region. The electron and the hole components of current density due to the generationrecombination in the depletion region is given as: ${ }^{82}$

$$
J_{\mathrm{GR}}= \begin{cases}\frac{q n_{\mathrm{in}} w V}{\left(V_{\mathrm{bi}}-V\right) \tau_{\mathrm{SRH}}} & V<0 \\ \frac{2 n_{\mathrm{in}} w k T}{\left(V_{\mathrm{bi}}-V\right) \tau_{\mathrm{SRH}}} \sinh \left(\frac{q V}{2 k T}\right) \quad V>0\end{cases}
$$

where $\tau_{\mathrm{SRH}}=1 / \sigma N_{\mathrm{f}} v_{\text {th }}$ is SRH generation-recombination lifetime of carriers. $\sigma=6.9591 \times 10^{-16} \mathrm{~cm}^{2}$ represents the capture cross section of minority carriers. $N_{\mathrm{f}}$ is the SRH trap density. $v_{\text {th }}=\left(3 k T / m_{\mathrm{n}}^{*}\right)^{1 / 2}$ is the thermal velocity of minority carriers.

The current related to TAT corresponds to the tunneling of electrons to the conduction band via a trap level within the bandgap. These trap states are the intermediate energy levels generated due to the existence of impurities in the material. The TAT component of current density is evaluated as: ${ }^{82}$

$$
J_{\mathrm{TAT}}=\frac{2 \pi^{2} q^{2} m_{\mathrm{n}}^{*} W_{c}^{2} N_{\mathrm{t}}\left(V_{\mathrm{bi}}-V\right) w}{h^{3}\left(\Delta E_{\mathrm{g}}-E_{\mathrm{t}}\right)} \mathrm{e}^{\left(-\frac{\sqrt{3} w \Delta \mathrm{E}_{\mathrm{g}}{ }^{2}}{8 \sqrt{2} P\left(V_{\mathrm{bi}}-V\right)} \alpha\left(\frac{E_{\mathrm{t}}}{\Delta E_{\mathrm{g}}}\right)\right)}
$$

where

$$
\begin{aligned}
\alpha\left(\frac{E_{\mathrm{t}}}{\Delta E_{\mathrm{g}}}\right)= & \frac{\pi}{2}+\sin ^{-1}\left( \pm 1 \pm 2 \frac{E_{\mathrm{t}}}{\Delta E_{\mathrm{g}}}\right) \\
& \pm\left(1-2 \frac{E_{\mathrm{t}}}{\Delta E_{\mathrm{g}}}\right) \sqrt{\frac{E_{\mathrm{t}}}{\Delta E_{\mathrm{g}}}\left(1-\frac{E_{\mathrm{t}}}{\Delta E_{\mathrm{g}}}\right)}
\end{aligned}
$$

Here, $N_{\mathrm{t}}$ is the trap density different from SRH trap density, and $h$ is the Planck's constant. $W_{\mathrm{c}}$ and $P$ represent matrix elements associated with the potential and interband matrix elements, respectively. The position of the trap levels in the bandgap is indicated by $E_{\mathrm{t}}$.

The high reverse bias causes bending in energy band to tunnel the electrons from valence band to the conduction band as shown in Fig. 1. This BTB current density is given by: ${ }^{22}$

$$
J_{\mathrm{BTB}}=\frac{q^{3} E V}{4 \pi^{2} \hbar^{2}} \sqrt{\frac{2 m_{\mathrm{n}}^{*}}{\Delta E_{\mathrm{g}}^{*}}} \mathrm{e}\left(-\frac{4 \sqrt{2 m_{\mathrm{n}}^{*} \Delta E_{\mathrm{g}}^{3}}}{3 q \hbar E}\right)
$$

where $\hbar=h / 2 \pi$ is the reduced Planck's constant, $E$ represents the electric field across the depletion region.

Fig. 3a shows the simulated current density $(J)$ as function of applied voltage varying from -1.0 to $0.3 \mathrm{~V}$. The results are obtained under dark condition, and at a radiation of incident power intensity $\left(P_{\text {in }}\right)$ of $1 \mathrm{~W} \mathrm{~cm}^{-2}$ at $20.6 \mu \mathrm{m}$. For the Mixed-Mode simulations of the circuit shown in Fig. 1c under dark condition, the values of $I_{\text {light }}, C_{\mathrm{j}}$, and $R_{\mathrm{sh}}$ are obtained at zero-bias condition. The proposed photodetector exhibits a low dark current density of $1.75 \times 10^{-14} \mu \mathrm{A} \mathrm{cm} \mathrm{cm}^{-2}$ and a photocurrent density of $8.33 \mu \mathrm{A} \mathrm{cm}^{-2}$ at zero-bias (self-powered mode) which in turn improves the signal-to-noise ratio (SNR), and hence specific detectivity. The simulated values of $J_{\mathrm{dark}}-V$ characteristic are well in accordance with the values obtained from the analytical modeling. The obtained $J_{\text {dark }}$ is smaller than that of the state-ofart photodetectors such as $\mathrm{Hg}_{1-x} \mathrm{Cd}_{x} \mathrm{Te}$ based IR photodetector, ${ }^{24}$ Gr-Silicon Schottky IR photodetector, ${ }^{1}$ Gr-Germanium Schottky IR photodetector, ${ }^{3}$ Gr-GaAs IR photodetector ${ }^{39}$ and armchair graphene nanoribbons IR photodetector. ${ }^{83}$

The $J_{\text {light }}-V$ characteristics under illumination at $20.6 \mu \mathrm{m}$ for different $P_{\text {in }}$ varying from $1 \mathrm{~mW} \mathrm{~cm}^{-2}$ to $2 \mathrm{~W} \mathrm{~cm}^{-2}$ are shown in Fig. $3 \mathrm{~b}$. The $J_{\text {light }}$ increases with the incident power, and shifts towards the positive voltage region due to unidirectional charge transport mechanism. The two important figure-of-merits to evaluate the electrical performance of photodetectors are $J_{\text {light }} /$ $J_{\text {dark }}$ ratio and linear dynamic range ${ }^{33}\left(\mathrm{LDR}(\mathrm{dB})=20 \log \left(J_{\text {light }} /\right.\right.$ $\left.J_{\text {dark }}\right)$ ). Fig. 3c shows the $J_{\text {light }}, J_{\text {light }} / J_{\text {dark }}$ ratio, and LDR for various $P_{\text {in }}$ values at zero-bias and $77 \mathrm{~K}$. The device exhibits $J_{\text {light }} / J_{\text {dark }}$ ratio of $4.8 \times 10^{14}$ and LDR of $293.55 \mathrm{~dB}$ at $2 \mathrm{~W} \mathrm{~cm}^{-2}$ in self-powered mode and are better than that of $\mathrm{Gr}-\mathrm{Si}$ based heterojunction photodetector. ${ }^{84,85}$ The photocurrent density $J_{\text {light }}$ and incident power $P_{\text {in }}$ satisfy the relationship ${ }^{86} J_{\text {light }} \propto$ $P_{\text {in }}{ }^{\alpha}$, where $\alpha$ is an empirical value related to the recombination process of the photoexcited carriers. From Fig. $3 c, \alpha=1.0$ is obtained for reverse biases varying from -1.0 to $0.0 \mathrm{~V}$. The linear response of photocurrent density as a function of incident power indicates that the recombination loss is negligible for the proposed heterojunction photodetector. Fig. 3d shows the current density, LDR, and effective or net resistance area 
product $(\mathrm{RA})_{\text {NET }}$ with respect to temperature variation at a bias of $-1.0 \mathrm{~V}$ and incident power of $1 \mathrm{~W} \mathrm{~cm}^{-2}$. The increase in temperature decreases the resistance and LDR, whereas, increases the current density. The $(\mathrm{RA})_{\mathrm{NET}}$ arises due to different current densities, i.e., $J_{\mathrm{DIFF}}, J_{\mathrm{GR}}, J_{\mathrm{TAT}}$ and $J_{\mathrm{BTB}}$, and can be written as:

$$
\frac{1}{(\mathrm{RA})_{\mathrm{NET}}}=\frac{1}{(\mathrm{RA})_{\mathrm{DIFF}}}+\frac{1}{(\mathrm{RA})_{\mathrm{GR}}}+\frac{1}{(\mathrm{RA})_{\mathrm{TAT}}}+\frac{1}{(\mathrm{RA})_{\mathrm{BTB}}}
$$

The simulated and analytical resistance area product of the proposed photodetector for different voltages varying from -1.0 to $0.3 \mathrm{~V}$ at $77 \mathrm{~K}$ is shown in Fig. 3a. The photodetector exhibits a resistance area product $\left(\left(\mathrm{R}_{0} \mathrm{~A}\right)_{\mathrm{NET}}=\left(\frac{\mathrm{d} J}{\mathrm{~d} V}\right)_{V=0}^{-1}\right)$ of $0.3 \mathrm{M} \Omega \mathrm{cm}^{2}$ in self-powered mode which in turn results in high specific detectivity.

\section{Optical characterization}

The optical analysis of proposed photodetector is performed by coupling the optical and basic semiconductor equations. The optical absorption coefficient of $\mathrm{n}-\mathrm{Hg}_{1-x} \mathrm{Cd}_{x} \mathrm{Te}$ material within the Kane region is calculated by Chu's empirical relation. ${ }^{\mathbf{8 7 , 8 8}}$ For the photon energy $E_{\mathrm{p}}<E_{\mathrm{gn}}$ (tail region) and $E_{\mathrm{p}}>E_{\mathrm{gn}}$ (Kane region), the absorption coefficient is approximated by:

$$
\alpha_{\mathrm{n}}(\lambda)= \begin{cases}\alpha_{0} \mathrm{e}^{(\delta / K T)\left(E_{\mathrm{p}}-E_{0}\right)} & E_{\mathrm{p}}<E_{\mathrm{gn}}(x, T) \\ \alpha_{\mathrm{g}}(x, T) \mathrm{e}^{\beta(x, T)\left(E_{\mathrm{p}}-E_{\mathrm{gn}}(x, T)\right)} & E_{\mathrm{p}}>E_{\mathrm{gn}}(x, T)\end{cases}
$$

where $\alpha_{0}=\mathrm{e}^{(-18.5+45.68 x)} ; E_{0}=-0.355+1.77 x$ the fitting parameters which vary with $x$ composition and

$$
\frac{\delta}{k T}=\frac{\ln \alpha_{\mathrm{g}}-\ln \alpha_{0}}{E_{\mathrm{g}}(x, T)-E_{0}}
$$

Here,

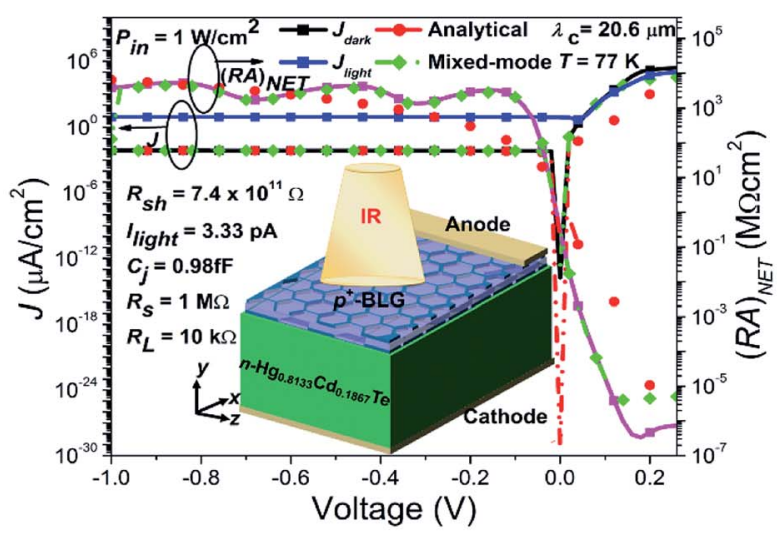

(a)

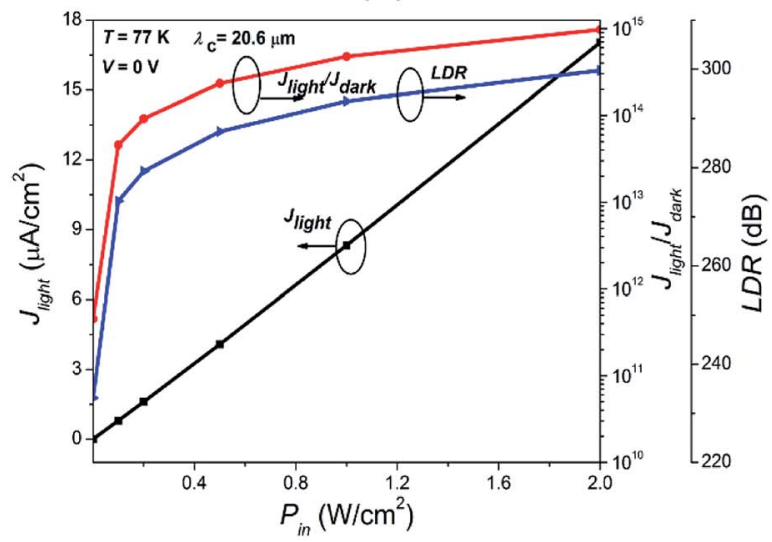

(c)

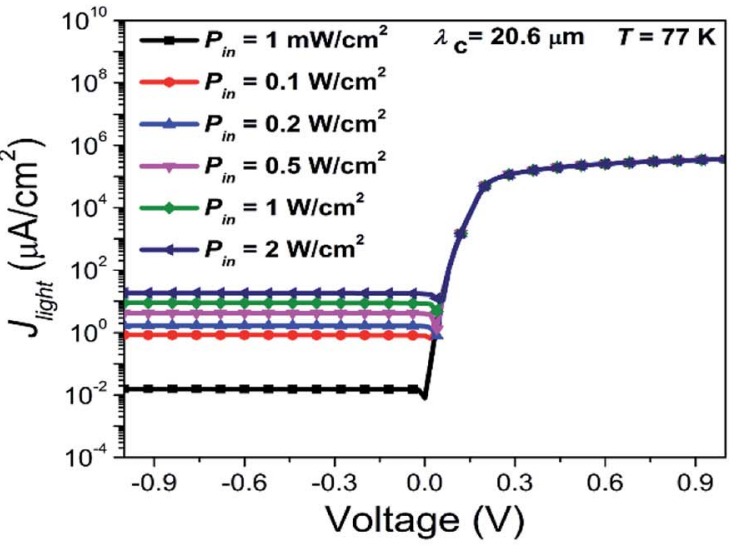

(b)

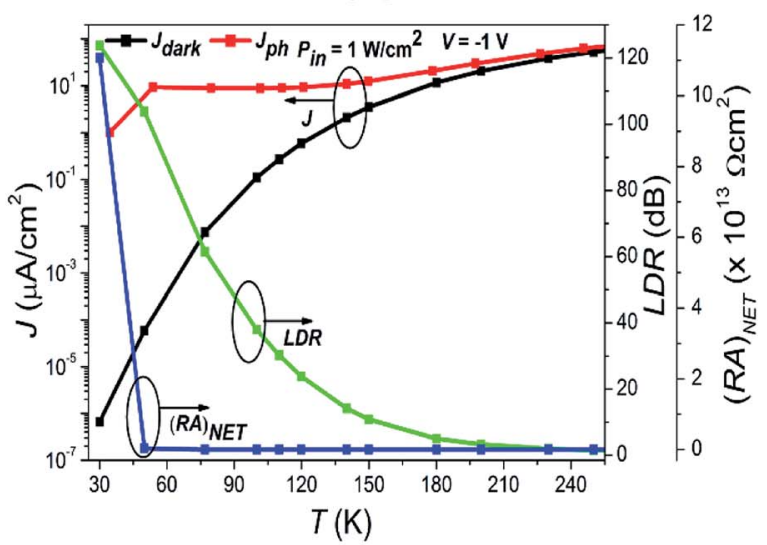

(d)

Fig. 3 The electrical characteristics of $\mathrm{p}^{+}-\mathrm{BLG} / \mathrm{n}-\mathrm{Hg}_{0.8133} \mathrm{Cd}_{0.1867} \mathrm{Te}$ heterojunction VLWIR photodetector at a cut-off wavelength ( $\lambda_{\mathrm{c}}$ ) of 20.6 $\mu \mathrm{m}$. (a) The current density $(\mathrm{J})$ and net resistance area product (RA) $)_{\mathrm{NET}}$ as a function of applied voltage $(\mathrm{V})$ at $77 \mathrm{~K}$ under dark and illumination conditions with $P_{\text {in }}=1 \mathrm{~W} \mathrm{~cm}{ }^{-2}$. Here, the values of $I_{\text {light }}, C_{\mathrm{j}}$, and $R_{\mathrm{sh}}$ are obtained at zero-bias condition and are used for Mixed-Mode simulation to evaluate device performances in the dark condition. The obtained results from Atlas and Mixed-Mode simulations are well in accordance with the results obtained from the analytical modeling. The inset shows the 3D schematic view of the photodetector. (b) The $J_{\text {light }}-V$ characteristics of the photodetector for different $P_{\text {in }}$ at $77 \mathrm{~K}$. (c) $J_{\text {light, }} J_{\text {light }} / J_{\text {dark }}$ ratio, and linear dynamic range (LDR) of the photodetector as a function of $P_{\text {in }}$ in self-powered mode (zero bias condition) at $77 \mathrm{~K}$. The $J_{\text {light }} / J_{\text {dark }}$ ratio and LDR increases exponentially with $P_{\text {in, }}$ whereas, $J_{\text {light }}$ increase linearly with $P_{\text {in. }}$ (d) The variation of current densities, LDR, and (RA) $)_{\text {NET }}$ with temperature at a bias of $-1.0 \mathrm{~V}$ under illumination of $1 \mathrm{~W} \mathrm{~cm}^{-2}$. The current densities increase exponentially, whereas LDR and $(R A)_{N E T}$ decreases with the increase in temperature due to the generation of thermally induced electron-hole pairs in addition to photoexcited carriers. 


$$
\begin{gathered}
\alpha_{\mathrm{g}}(x, T)=-65+1.88 T+(8694-10.314 T) x \\
\beta(x, T)=-1+0.083 T+(21-0.13 T) x
\end{gathered}
$$

In order to compute the optical characteristics, complex refractive indices are described for both the BLG and MCT. The wavelength $(\lambda)$ dependent complex refractive index for $\mathrm{Gr}$ is calculated by ${ }^{42} n_{\mathrm{Gr}}(\lambda)=3.0+i 1.8153 \lambda$, whereas, absorption coefficient is approximated by $\alpha_{\mathrm{p}^{+}}(\lambda)=1.8153 \times 4 \pi / \lambda$. The complex refractive index of MCT as a function of $x$ composition and temperature is given as: ${ }^{89}$

$$
n_{\mathrm{Hg}_{1-x} \mathrm{Cd}_{x} \mathrm{Te}}(\lambda, T)=\sqrt{A+\frac{B}{\left(1-\left(\frac{C}{\lambda}\right)^{2}\right)}+D \lambda^{2}}
$$

where

$$
\begin{aligned}
& A=13.173-9.852 x+2.909 x^{2}+10^{-3}(300-T) \\
& B=0.83-0.246 x-0.0961 x^{2}+8 \times 10^{-4}(300-T) \\
& C=6.706-14.437 x+8.531 x^{2}+7 \times 10^{-4}(300-T) \\
& D=1.953 \times 10^{-4}-0.00128 x+1.853 \times 10^{-4} x^{2}
\end{aligned}
$$

The imaginary part of the refractive index for MCT depends on the wavelength and absorption as. ${ }^{24} K=\lambda \alpha_{n}(\lambda) / 4 \pi$.

The spectral response of the proposed photodetector as a function of wavelength is shown in Fig. S1. $\dagger$ The quantum efficiency $(\mathrm{QE})$, photocurrent responsivity $\left(R_{\mathrm{i}}\right)$, specific detectivity $\left(D^{*}\right)$, and noise equivalent power (NEP) of proposed photodetector are evaluated using computer simulations. The two types of quantum efficiencies, i.e. internal $\mathrm{QE}\left(\mathrm{QE}_{\mathrm{int}}\right)$ and external $\mathrm{QE}\left(\mathrm{QE}_{\text {ext }}\right)$ are often considered for a photodetector. The $\mathrm{QE}_{\text {int }}$ determines the internal photocurrent responsivity $\left(R_{\mathrm{i}}^{\mathrm{int}}\right)$, whereas $\mathrm{QE}_{\text {ext }}$ gives the external photocurrent responsivity $\left(R_{\mathrm{i}}^{\text {ext }}\right)$. The $\mathrm{QE}_{\text {ext }}, R_{\mathrm{i}}^{\text {ext }}, D^{*}$, and NEP of the device are further evaluated using the analytical model. The $\mathrm{QE}_{\text {ext }}$ measures the wavelength dependent gain of the photodetector and can be given as ${ }^{32}$

$$
\begin{aligned}
\mathrm{QE}_{\mathrm{ext}} & =\mathrm{CM}(V, T) \times \frac{h c J_{\lambda}}{q \lambda P_{\text {in }}} \times 100 \% \\
& =\mathrm{CM}(V, T) \times \frac{1.24 J_{\lambda}}{\lambda P_{\text {in }}} \times 100 \%
\end{aligned}
$$

where CM represents the hot carrier multiplication factor ${ }^{69-74}$ which is a function of bias voltage and ambient temperature, $c$ is the speed of light, $J_{\lambda}$ is the photocurrent density, and $\lambda$ represents the wavelength of the incident radiation.

The net $\mathrm{QE}_{\text {ext }}$ of the photodetector comprises of neutral $\mathrm{p}^{+}$$\left(\mathrm{QE}_{\text {ext }}\right)_{\mathrm{p}^{+}}$, neutral $\mathrm{n}-\left(\mathrm{QE}_{\text {ext }}\right)_{\mathrm{n}}$, and the depletion $\left(\mathrm{QE}_{\text {ext }}\right)_{\mathrm{dep}}$ regions, and can be written as: ${ }^{24,90-92}$

$$
\mathrm{QE}_{\mathrm{ext}}=\mathrm{CM}(V, T) \times\left(\left(\mathrm{QE}_{\mathrm{ext}}\right)_{\mathrm{p}^{+}}+\left(\mathrm{QE}_{\mathrm{ext}}\right)_{\mathrm{n}}+\left(\mathrm{QE}_{\mathrm{ext}}\right)_{\mathrm{dep}}\right)
$$

where

$$
\begin{aligned}
&\left(\mathrm{QE}_{\mathrm{ext}}\right)_{\mathrm{p}^{+}}= \frac{\left(1-R_{\mathrm{p}^{+}}\right) \alpha_{\mathrm{p}^{+}} L_{\mathrm{n}}}{\alpha_{\mathrm{p}^{+}}{ }^{2} L_{\mathrm{n}}^{2}-1} \mathrm{e}^{-\left(\alpha_{\mathrm{p}^{+}} t_{\mathrm{p}^{+}}+\alpha_{\mathrm{n}} x_{\mathrm{n}}\right)} \\
& \times\left[\frac{\left(\gamma_{\mathrm{n}}-\alpha_{\mathrm{p}^{+}} L_{\mathrm{n}}\right) \mathrm{e}^{-\alpha_{\mathrm{n}}\left(d-x_{\mathrm{n}}\right)}-\left\{\gamma_{\mathrm{n}} \cosh \left(\frac{d-x_{\mathrm{n}}}{L_{\mathrm{n}}}\right)+\sinh \left(\frac{d-x_{\mathrm{n}}}{L_{\mathrm{n}}}\right)\right\}}{\cosh \left(\frac{d-x_{\mathrm{n}}}{L_{\mathrm{n}}}\right)+\gamma_{\mathrm{n}} \sinh \left(\frac{d-x_{\mathrm{n}}}{L_{\mathrm{n}}}\right)}\right. \\
&\left.+\alpha_{\mathrm{p}^{+}} L_{\mathrm{n}}\right] \\
&\left(\mathrm{QE}_{\mathrm{ext}}\right)_{\mathrm{n}}=\frac{\left(1-R_{\mathrm{p}^{+}}\right)\left(1-R_{\mathrm{n}}\right) \alpha_{\mathrm{n}} L_{\mathrm{p}}}{\alpha_{\mathrm{n}}^{2} L_{\mathrm{p}}^{2}-1} \\
& \times\left[\frac{\left(\alpha_{\mathrm{n}} L_{\mathrm{p}}+\gamma_{\mathrm{p}}\right)-\mathrm{e}^{-\alpha_{\mathrm{n}} x_{\mathrm{p}^{+}}}\left\{\gamma_{\mathrm{p}} \cosh \left(\frac{x_{\mathrm{p}^{+}}}{L_{\mathrm{p}}}\right)+\sinh \left(\frac{x_{\mathrm{p}^{+}}}{L_{\mathrm{p}}}\right)\right\}}{\cosh \left(\frac{x_{\mathrm{p}^{+}}}{L_{\mathrm{p}}}\right)+\gamma_{\mathrm{p}} \sinh \left(\frac{x_{\mathrm{p}^{+}}}{L_{\mathrm{p}}}\right)}\right. \\
&\left.-\alpha_{\mathrm{n}} L_{\mathrm{p}} \mathrm{e}^{-\alpha_{\mathrm{n}} x_{\mathrm{p}^{+}}}\right]
\end{aligned}
$$

and

$$
\left(\mathrm{QE}_{\text {ext }}\right)_{\mathrm{dep}}=\left(1-R_{\mathrm{p}+}\right)\left(1-R_{\mathrm{n}}\right)\left[\mathrm{e}^{-\alpha_{\mathrm{p}^{+}}+x_{\mathrm{p}^{+}}}-\mathrm{e}^{-\alpha_{\mathrm{n}}\left(t_{\mathrm{p}^{+}}+x_{\mathrm{n}}\right)}\right]
$$

Here, $R_{\mathrm{p}^{+}}$and $R_{\mathrm{n}}$ are the Fresnel reflection coefficients at the entrance and $\mathrm{p}^{+}-\mathrm{n}$ interfaces, respectively.

The photocurrent responsivity is a ratio of photocurrent to the incident light power, whereas, quantum efficiency measures the sensitivity of the photodetector. On the other hand, the specific detectivity describes the smallest signal that a photodetector can detect, however, noise equivalent power is the minimum incident signal that a photodetector can resolve from the noise. The $\mathrm{QE}_{\text {int }}$ of the IPE process is the number of carriers emitted to $\mathrm{HgCdTe}$ per absorbed photon, and $\mathrm{QE}_{\text {ext }}$ is the number of carriers emitted to HgCdTe per incident photon. The $R_{\mathrm{i}}^{\text {int }}, R_{\mathrm{i}}^{\text {ext }}, D^{*}$, and NEP are calculated using following relations: $:^{3,24,32,33,93}$

$$
\begin{gathered}
R_{\mathrm{i}}^{\text {int }}=\mathrm{QE}_{\text {int }}\left(\frac{q \lambda}{h c}\right)=\mathrm{QE}_{\text {int }}\left(\frac{\lambda}{1.24}\right) \mathrm{A} \mathrm{W}^{-1} \\
R_{\mathrm{i}}^{\text {ext }}=\mathrm{QE}_{\text {ext }}\left(\frac{\lambda}{1.24}\right) \mathrm{A} \mathrm{W}^{-1} \\
D^{*}=\frac{R_{\mathrm{i}}^{\text {ext }}}{2} \sqrt{\frac{\left(R_{0} A\right)_{\mathrm{NET}}}{k T}} \mathrm{~cm} \mathrm{~Hz}^{1 / 2} \mathrm{~W}^{-1} \\
\mathrm{NEP}=\frac{\sqrt{\Delta f A}}{D^{*}} \mathrm{~W}
\end{gathered}
$$

where $\Delta f$ and $A$ are the bandwidth, and active area, respectively. Here, NEP is estimated at a unity bandwidth, i.e. $\Delta f=1 \mathrm{~Hz}$.

Fig. 4a shows the variation of $\mathrm{QE}_{\text {ext }}, R_{\mathrm{i}}^{\text {ext }}$, and NEP for the proposed photodetector as a function of wavelength at a of $-0.5 \mathrm{~V}$ and a radiation of $1 \mathrm{~W} \mathrm{~cm}^{-2}$ at $20.6 \mu \mathrm{m}$ and $77 \mathrm{~K}$. The 
device exhibits a high $\mathrm{QE}_{\text {int }} \sim 99.49 \%$ (Fig. S1b $\dagger$ ), $\mathrm{QE}_{\mathrm{ext}} \sim 89 \%$, $R_{\mathrm{i}}^{\text {int }} \sim 13.26 \mathrm{~A} \mathrm{~W}^{-1}$ (Fig. $\mathrm{S} 1 \mathrm{~b} \dagger$ ), $R_{\mathrm{i}}^{\text {ext }} \sim 9.1 \mathrm{~A} \mathrm{~W}^{-1}, D^{*} \sim 7.6 \times$ $10^{13} \mathrm{~cm} \mathrm{~Hz}^{1 / 2} \mathrm{~W}^{-1}$ (Fig. S2a $\dagger$ ), and low value of NEP $\sim 8.3 \times$ $10^{-18} \mathrm{~W}$.

The influence of reverse bias voltage, incident power intensity, and temperature on the maximum external quantum efficiency $\left(\mathrm{QE}_{\text {ext(max) }}\right)$, maximum external photocurrent responsivity, $R_{\mathrm{i}(\max )}^{\text {ext }}$ and minimum NEP $\left(\mathrm{NEP}_{(\min )}\right)$ under IR illumination are shown in Fig. 4b-d, respectively. The increase in reverse bias in Fig. $4 \mathrm{~b}$, increases the $\mathrm{QE}_{\text {ext(max) }}$, and $R_{\mathrm{i}(\max )}^{\text {ext }}$ resulting in a lower NEP. The increase in both $\mathrm{QE}_{\text {ext(max })}$, and $R_{\mathrm{i}(\max )}^{\text {ext }}$ with the reverse bias voltage is mainly due to the increased drift velocity of the photo-induced charge carriers along with the increased probability of exciton separation and acceleration with the bias voltage, which eventually contribute to the total photocurrent in the external circuit. The increase in $\mathrm{QE}_{\text {ext }}$ is attributed to the carriers passing thin depletion region multiple times at a certain reverse bias. ${ }^{32}$ Fig. $4 \mathrm{c}$ demonstrates the variation of incident power suggesting increase in $R_{\mathrm{i}}^{\text {ext }}$ due to the increase in photocurrent which decreases both $\mathrm{QE}_{\text {ext }}$ and NEP. The decrease in $\mathrm{QE}_{\text {ext }}$ with incident power could also be attributed due to the self-inducedheating increase in the carrier scattering and hence the rate of charge carrier recombination. Furthermore, the increase in reverse bias and incident power results in improved $D^{*}$ as shown in Fig. S2b and c, $\uparrow$ respectively.

The effect of temperature variation on optical parameters of the device is shown in Fig. 4d. The $\mathrm{QE}_{\text {ext(max) }}$ increases from 10.68 to $3337.70 \%$, whereas the $R_{\mathrm{i}(\max )}^{\mathrm{ext}}$ increases from 0.51 to $62.36 \mathrm{~A} / \mathrm{W}$ for the temperatures varying from 30 to $250 \mathrm{~K}$. The maximum $D^{*}\left(D_{\max }^{*}\right)$ changes from $3.8 \times 10^{15}$ to $8.08 \times 10^{12} \mathrm{~cm}$ $\mathrm{Hz}^{1 / 2} \mathrm{~W}^{-1}$ for temperatures $30-180 \mathrm{~K}$, and from $3.04 \times 10^{11}$ to $1.29 \times 10^{13} \mathrm{~cm} \mathrm{~Hz}^{1 / 2} \mathrm{~W}^{-1}$ for the temperature range $200-250 \mathrm{~K}$ (see Fig. S2d $\dagger$ ). Accordingly, $\mathrm{NEP}_{(\min )}$ varies from $1.66 \times 10^{-19}$ to $4.90 \times 10^{-17} \mathrm{~W}$ for the temperature range $30-250 \mathrm{~K}$ as shown in Fig. 4d. The proposed photodetector demonstrates a $\mathrm{QE}_{\text {ext(max) }}, R_{\mathrm{i}(\max )}^{\text {ext }}, D_{(\max )}^{*}$ and $\mathrm{NEP}_{(\min )}$ of $3337.70 \%, 62.36 \mathrm{~A}$ $\mathrm{W}^{-1}, 1.29 \times 10^{13} \mathrm{~cm} \mathrm{~Hz}^{1 / 2} \mathrm{~W}^{-1}$ and $4.90 \times 10^{-17} \mathrm{~W}$, respectively, at near room temperature.

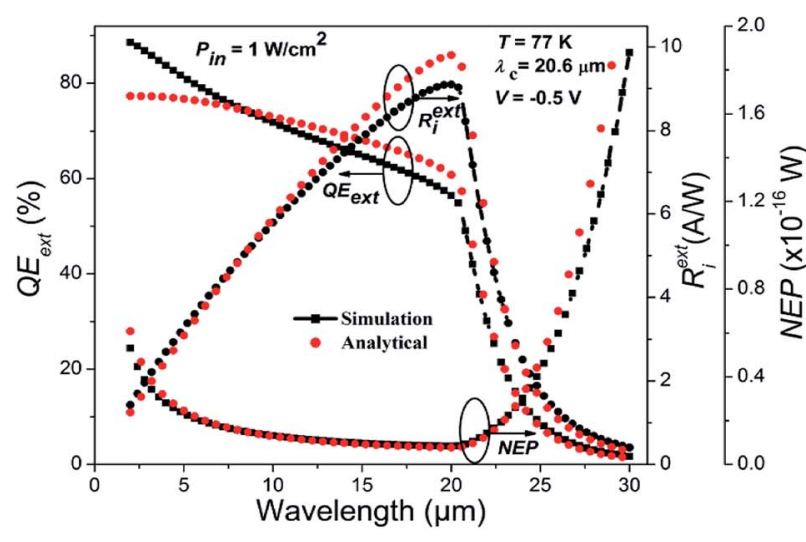

(a)

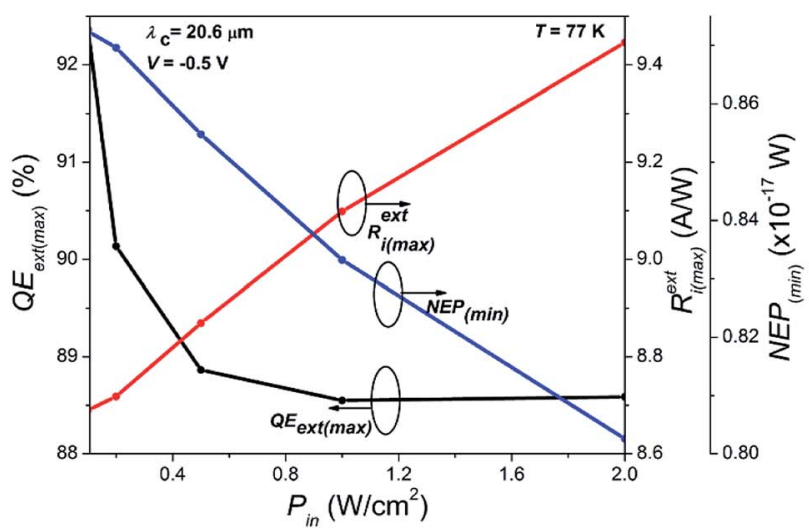

(c)

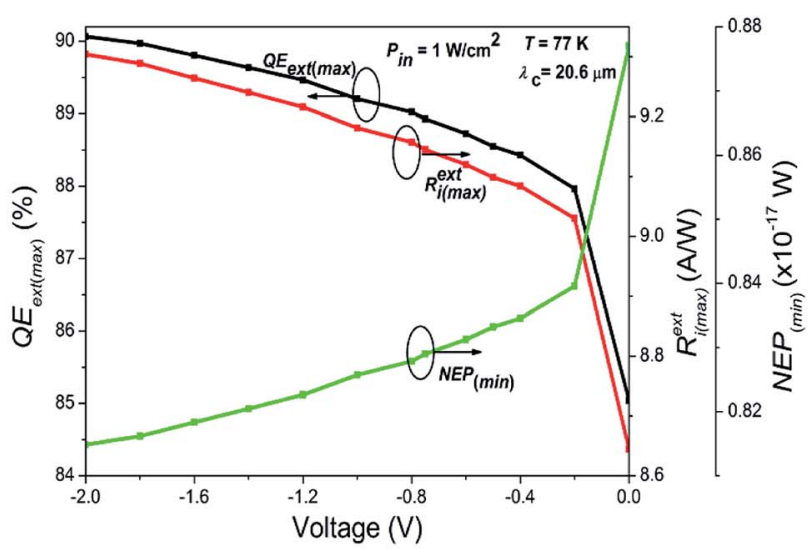

(b)

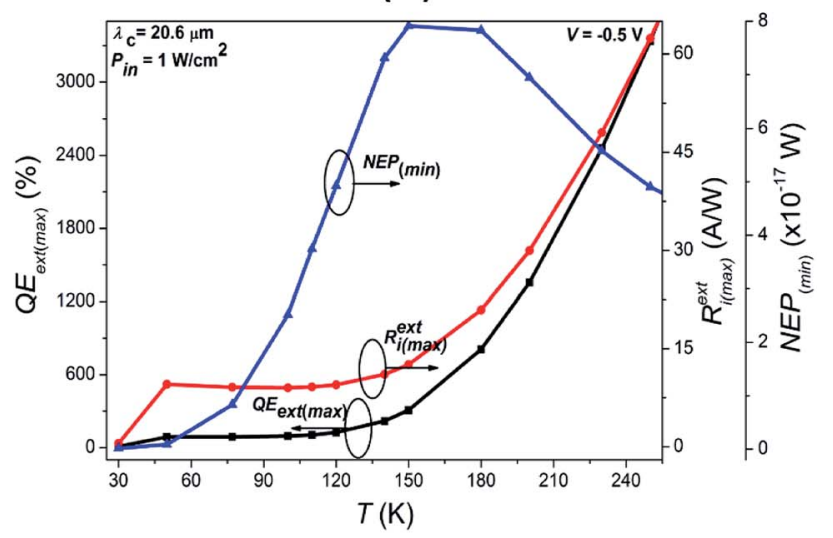

(d)

Fig. 4 The optical characteristics of $\mathrm{p}^{+}-\mathrm{BLG} / \mathrm{n}-\mathrm{Hg}_{0.8133} \mathrm{Cd}_{0.1867}$ Te photodetector at a cut-off wavelength $\left(\lambda_{\mathrm{c}}\right)$ of $20.6 \mu \mathrm{m}$. (a) The external quantum efficiency $\left(Q E_{\text {ext }}\right)$, external photocurrent responsivity, $\left(R_{\mathrm{i}}^{\text {ext }}\right)$ and noise equivalent power (NEP) as a function of wavelength with $P_{\text {in }}=1 \mathrm{~W}$ $\mathrm{cm}^{-2}, V=-0.5 \mathrm{~V}$ at $77 \mathrm{~K}$. The results are well in accordance with the results obtained from analytical modeling. (b) The $Q E_{\text {ext(max }),} R_{i(\max )}$, and $\mathrm{NEP}_{(\min )}$ as a function of bias voltage with $P_{\text {in }}=1 \mathrm{~W} \mathrm{~cm}^{-2}$ at $77 \mathrm{~K}$. The $\mathrm{QE}_{\text {ext(max) }}$ and, $R_{\mathrm{i}(\max )}^{\text {ext }}$ increases with the bias voltage, whereas $\mathrm{NEP}$ (min)

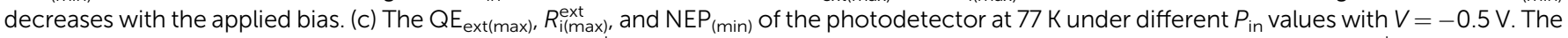

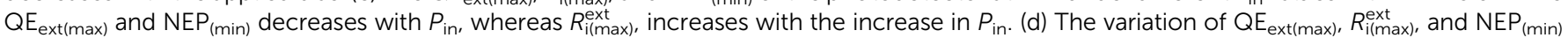
with temperature under $-0.5 \mathrm{~V}$ bias at $1 \mathrm{~W} \mathrm{~cm}^{-2}$. The $\mathrm{QE}_{\mathrm{ext}(\max )}$ and, $R_{\mathrm{i}(\max )}^{\text {ext }}$ both increases with the increase in temperature, whereas $\mathrm{NEP}_{(\min )}$ initially increases upto $150 \mathrm{~K}$ and improves thereafter. 


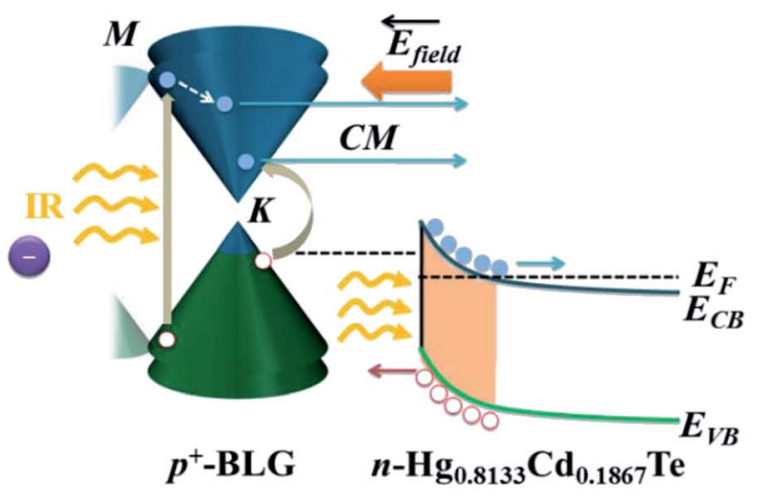

(a)

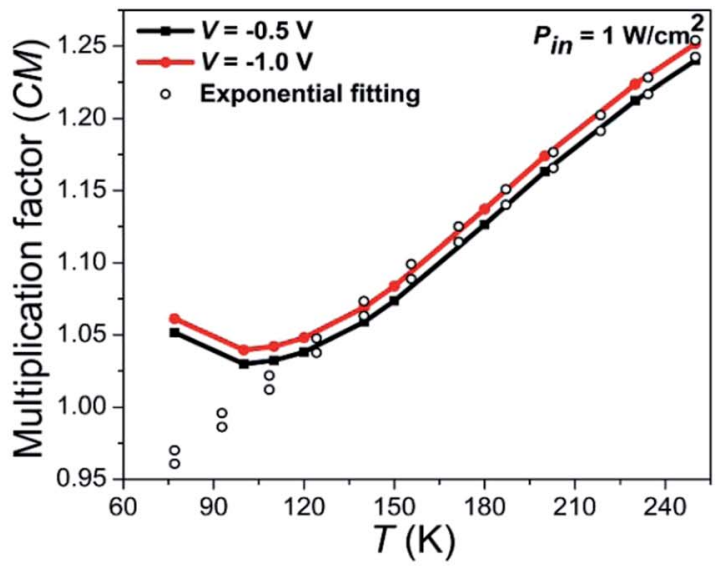

(b)

Fig. 5 (a) The energy band diagram of $\mathrm{p}^{+}-\mathrm{BLG} / \mathrm{n}-\mathrm{Hg}_{0.8133} \mathrm{Cd}_{0.1867} T$ e heterojunction based VLWIR photodetector under illumination and reverse bias condition showing carrier multiplication (CM). (b) The carrier multiplication factor as a function of temperature at -0.5 and $-1.0 \mathrm{~V}$ under illumination of $1 \mathrm{~W} \mathrm{~cm}{ }^{-2}$. The CM factor increases exponentially with the increase in temperature.

The high values of $\mathrm{QE}_{\text {ext }}$ more than $100 \%$ are generally associated with the well-known carrier multiplication effect in graphene. ${ }^{69-74}$ Such multiple hot-carrier generation can be explained with the schematic representation of energy band diagram of proposed device as shown in Fig. 5a. The incident optical energy excites an electron in the valence band to the higher conduction state of the graphene which further excites another valence band electron to conduction band as shown in Fig. 5a. Therefore, generation of multiple hot-carriers in graphene with single incident photon is due to impact ionization. Such carrier multiplication effect is observed to be increasing with doping in graphene. ${ }^{74}$ Moreover, under the illumination of high optical energy, light can also be absorbed in both the $M$ and $K$-points of the Brillouin zone in graphene resulting in enhanced carrier multiplication effect. ${ }^{33}$

The combined effect of carrier multiplication (in graphene) and presence of high electric field across the junction causes transport of multiple electrons (holes) to the positive (negative)

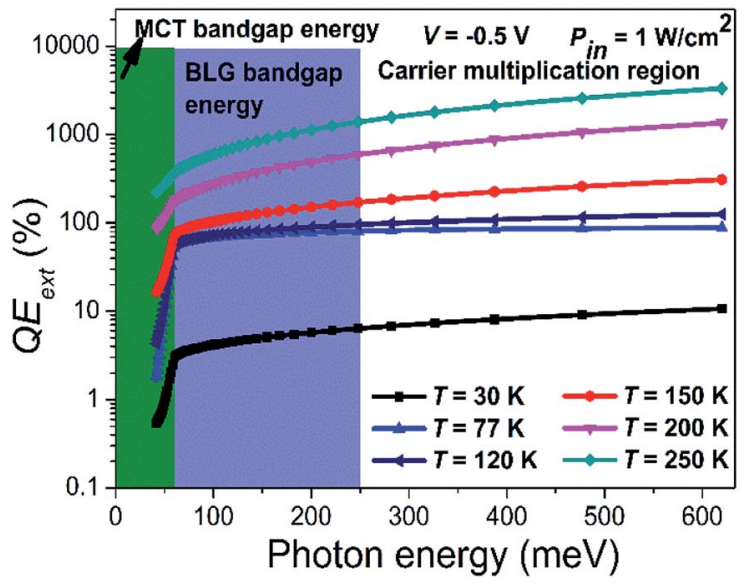

Fig. 6 The $Q E_{\text {ext }}$ as a function of photon energy with an incident power of $1 \mathrm{~W} \mathrm{~cm} \mathrm{~cm}^{-2}$ at $-0.5 \mathrm{~V}$ bias for different temperatures varying from 30 to $250 \mathrm{~K}$. The $Q E_{\text {ext }}$ exceeds $100 \%$ due to the generation of long lifetime of photo-induced hot carriers in VLWIR region. bias electrodes which finally contributes to the net enhanced photocurrent and $\mathrm{QE}_{\text {ext }}$.

The $\operatorname{CM}(V, T)$ can be estimated from the simulated $J-V$ characteristics under dark and illumination conditions at different temperatures as: ${ }^{27}$

$$
\mathrm{CM}(V, T)=\frac{J_{\text {light }}(V, T)-J_{\text {dark }}(V, T)}{J_{\text {light }}(V=0, T)-J_{\text {dark }}(V=0, T)}
$$

Fig. $5 \mathrm{~b}$ shows the estimated CM factor at -0.5 and $-1.0 \mathrm{~V}$ bias as a function of temperature. The CM factor is observed to be increasing with ambient temperature exponentially which is attributed to the temperature dependence of the semiconductor current according to eqn (29). The CM factor is observed to be varying in the range of 1.05-1.24 and 1.06-1.25 at -0.5 and $-1.0 \mathrm{~V}$, respectively, for the temperature range 77 to $250 \mathrm{~K}$. With increasing reverse bias, the probability of carrier recombination

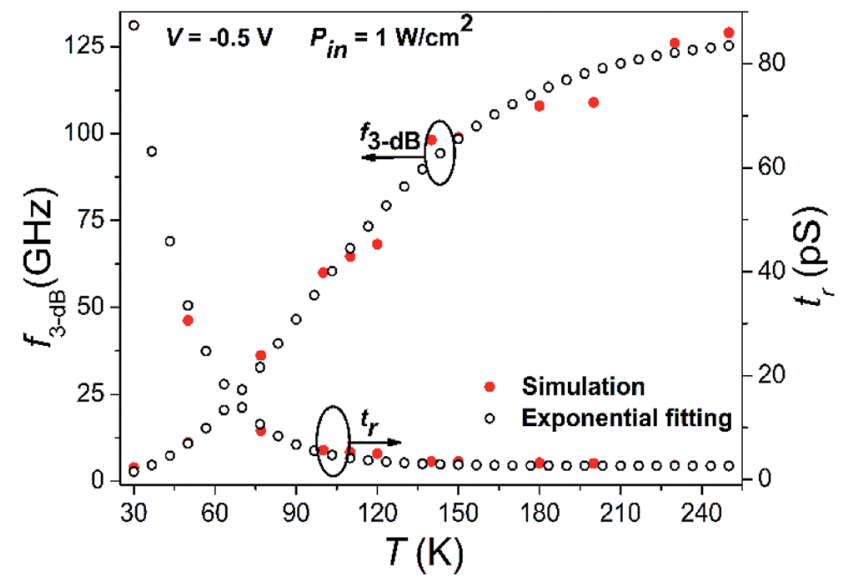

Fig. 7 The $f_{3 \mathrm{~dB}}$ and $t_{\mathrm{r}}$ as a function of temperature with $V=-0.5 \mathrm{~V}$ and $P_{\text {in }}=1 \mathrm{~W} \mathrm{~cm}^{-2}$. The $f_{3 \mathrm{~dB}}$ rise exponentially with temperature, whereas, $t_{r}$ decay exponentially with temperature, due to increase in depletion length at higher temperatures which in turn reduces space-charge capacitance. 


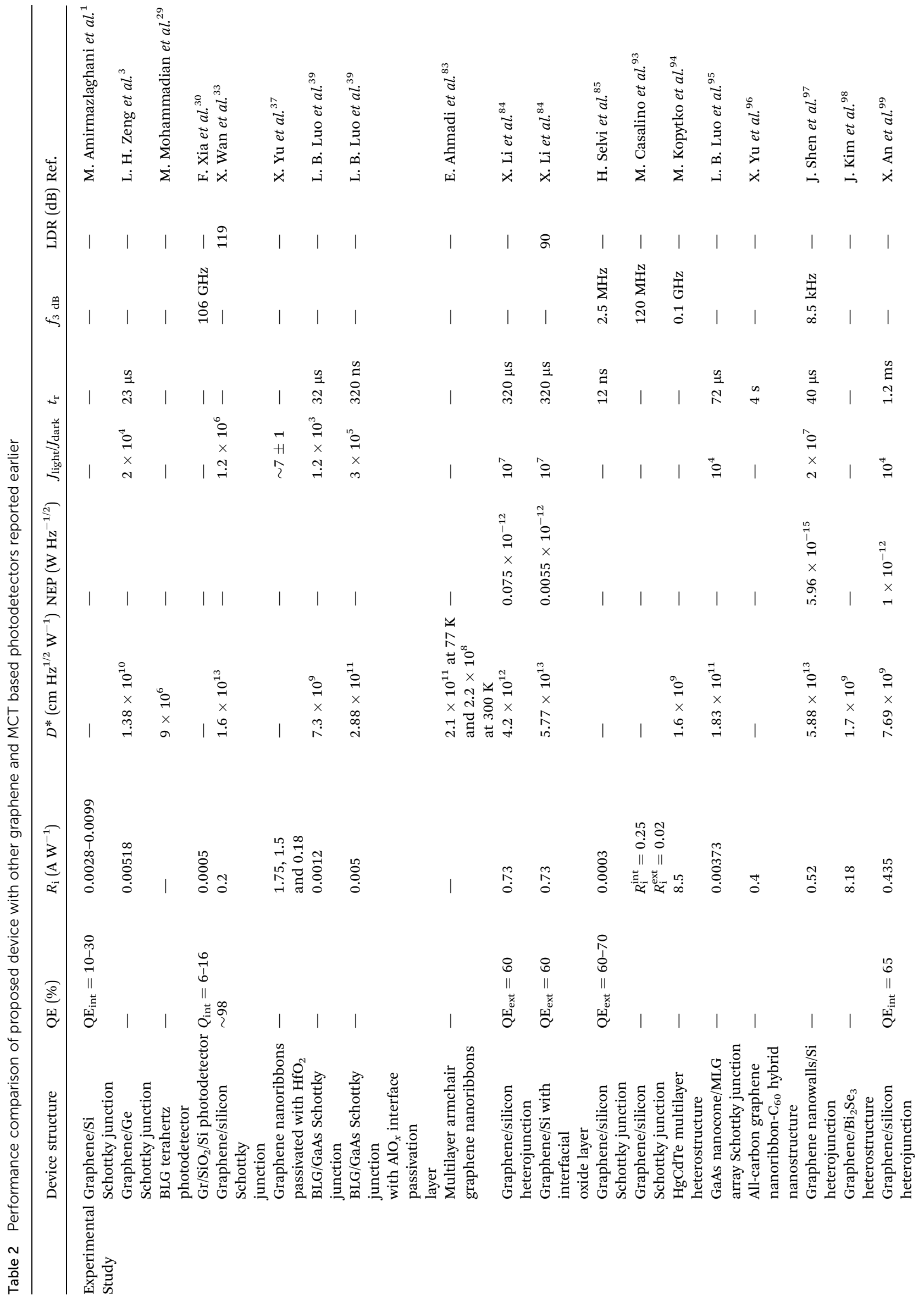




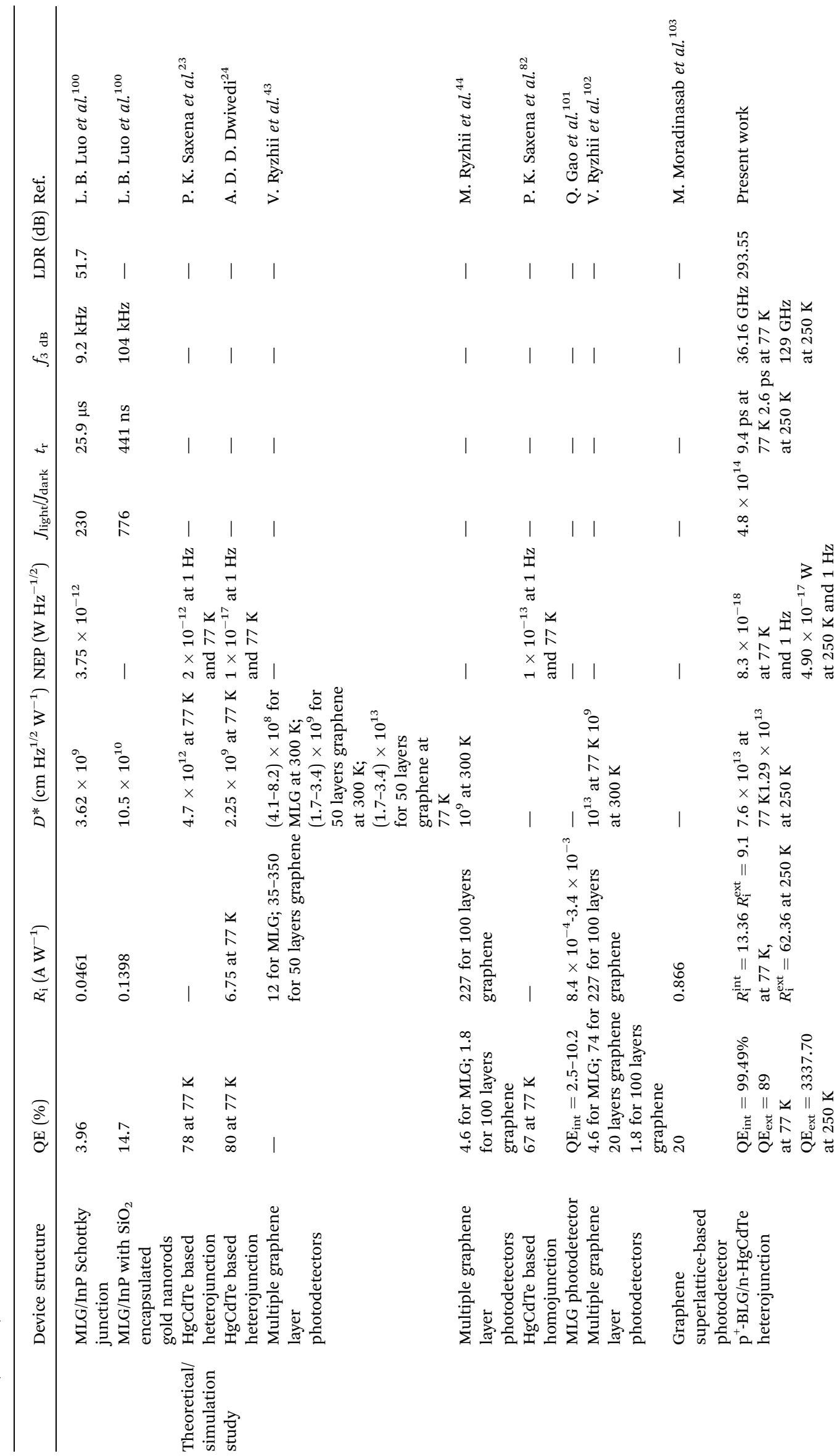


decreases resulting in long life-time of photo-generated carriers and, hence, improves effective carrier multiplication in the device. In our case, the obtained values of hot CM factor for $\mathrm{p}^{+}$doped graphene are well in accordance with the previously reported experimental values. ${ }^{73,74}$

The variation of $\mathrm{QE}_{\text {ext }}$ as a function of photon energy is shown in Fig. 6. The $\mathrm{QE}_{\text {ext }}$ increases with the incident photon energy due to prominent hot CM under illumination with higher energy than the band-gap of BLG. On the other hand, photon energy smaller than the BLG band-gap lowers the $\mathrm{QE}_{\text {ext }}$ which is attributed to the decreased carrier multiplication as shown in Fig. 6. Furthermore, the external reverse bias provides a high electric field to the device which increases the probability of electron-hole pair separation and enhances drift-velocity of the photogenerated charge carriers in both graphene and MCT.

In addition, we have estimated the shot (quantum) and Johnson-Nyquist (thermal) noise, ${ }^{93}$ which also dominate in the photodetector. Accordingly, the shot $\left(i_{\mathrm{s}}\right)$ and Johnson-Nyquist $\left(i_{\mathrm{j}}\right)$ noise currents are calculated by ${ }^{\mathbf{8 2}} i_{\mathrm{s}}=\sqrt{2 q\left(I_{\text {light }}+I_{\text {dark }}\right) \Delta f}$ and $i_{\mathrm{j}}=\sqrt{(4 k T \Delta f) / R_{\mathrm{NET}}}$, where $I_{\mathrm{dark}}$ is the dark current $R_{\mathrm{NET}}=$ $(\mathrm{d} I / \mathrm{d} V)^{-1}$, is the net resistance of photodetector in dark condition at reverse bias and $\Delta f=1 \mathrm{~Hz}$ is the bandwidth. The total noise current $\left(i_{\mathrm{n}}\right)^{93}$ and $\mathrm{SNR}^{82}$ are given by $i_{\mathrm{n}}=i_{\mathrm{s}}+i_{\mathrm{j}}$ and $\operatorname{SNR}(\mathrm{dB})=10 \log \left(\frac{\frac{1}{2}\left(\frac{\mathrm{QE}_{\mathrm{ext}} P_{\mathrm{in}} \lambda}{1.24}\right)}{i_{\mathrm{n}}}\right)$

The estimated values of $i_{\mathrm{n}}$ and SNR are $1.06 \mathrm{fA}$ and $156.18 \mathrm{~dB}$, respectively, for $-0.5 \mathrm{~V}$ bias and a radiation of $1 \mathrm{~W} \mathrm{~cm}^{-2}$ at $20.6 \mu \mathrm{m}$ and $77 \mathrm{~K}$. Fig. 7 shows the $3 \mathrm{~dB}$ cut-off frequency $\left(f_{3} \mathrm{~dB}\right)$ and response time $\left(t_{\mathrm{r}}\right)$ as a function of temperature at $-0.5 \mathrm{~V}$ bias with incident power of $1 \mathrm{~W} \mathrm{~cm}{ }^{-2}$. Beyond $3 \mathrm{~dB}$ cut-off frequency, the current/gain starts rolling-off quickly. The response time suggests the increase in output signal from $10-90 \%$ of the maximum value and is related to $3 \mathrm{~dB}$ cut-off $\mathrm{as}^{85}$

$$
t_{\mathrm{r}}=\frac{0.34}{f_{3 \mathrm{~dB}}} \mathrm{~s}
$$

The results suggest exponential increase in $3 \mathrm{~dB}$ cut-off frequency from 3.89 to $129 \mathrm{GHz}$ due to the existence of high saturation velocity and high carrier mobility, whereas $t_{\mathrm{r}}$ decreases from 87.4 to 2.6 ps as shown in Fig. 7. The reduction in depletion (space-charge) capacitance and increase in depletion length is responsible for obtaining larger cut-off frequency. ${ }^{\mathbf{8 2}}$ It can be further increased with the increase in reverse bias voltage and reduction in the device active area inducing reduced capacitance. To the best of our knowledge, the obtained results for the proposed photodetector are better than that of previously reported graphene

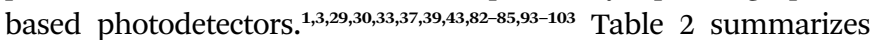
the key parameters of our proposed device with other MCT and graphene based photodetectors reported earlier.

\section{Conclusions}

In summary, we have demonstrated a high-performance $\mathrm{p}^{+}$-BLG and few layer graphene $/ \mathrm{n}-\mathrm{Hg}_{0.8133} \mathrm{Cd}_{0.1867} \mathrm{Te}$ heterojunction
VLWIR photodetector. The various electrical and optical characteristic parameters are computed and analysed using computer simulations and are further validated by an analytical model based on drift-diffusion, tunneling and Chu's methods. The dark current density is reduced due to lower thermogeneration rate of BLG and MCT heterostructure, offering the high quantum efficiency, high photocurrent responsivity, high specific detectivity, low noise equivalent power, low noise current, and better signal to noise ratio. The near room temperature external quantum efficiency of $3337.70 \%$ and responsivity of $62.36 \mathrm{~A} \mathrm{~W}^{-1}$ at $-0.5 \mathrm{~V}$ bias are achieved in addition to a higher $3 \mathrm{~dB}$ cut-off frequency $(\sim 129 \mathrm{GHz})$ and short response time ( $\sim 2.6 \mathrm{ps})$. Such superior performances are obtained due to hot carrier multiplication mechanism in graphene. The obtained results suggest the utilisation of $\mathrm{p}^{+}-\mathrm{BLG} / \mathrm{n}$ $\mathrm{Hg}_{0.8133} \mathrm{Cd}_{0.1867} \mathrm{Te}$ heterostructure for next-generation highperformance, ultra-low-power, low noise, and cost effective IR photodetection.

\section{Conflicts of interest}

There are no conflicts to declare.

\section{Acknowledgements}

Authors would like to thank P. K. Saxena at Technext Lab (P) Limited, Lucknow; A. D. D. Dwivedi at Poornima University, Jaipur; and A. Das at University of Calcutta, Kolkata, India for technical discussions.

\section{References}

1 M. Amirmazlaghani, F. Raissi, O. Habibpour, J. Vukusic and J. Stake, IEEE J. Quantum Electron., 2013, 49, 589-594.

2 S. Assefa, F. Xia and Y. A. Vlasov, Nature, 2010, 464, 80-84.

3 L. H. Zeng, M. Z. Wang, H. Hu, B. Nie, Y. Q. Yu, C. Y. Wu, L. Wang, J. G. Hu, C. Xie, F. X. Liang and L. B. Luo, ACS Appl. Mater. Interfaces, 2013, 5, 9362-9366.

4 A. Rogalski, Prog. Quantum Electron., 2003, 27, 59-210.

5 J. Yoon, S. Jo, I. S. Chun, I. Jung, H. S. Kim, M. Meitl, E. Menard, X. Li, J. J. Coleman, U. Paik and J. A. Rogers, Nature, 2010, 465, 329-333.

6 J. Miao, W. Hu, N. Guo, Z. Lu, X. Liu, L. Liao, P. Chen, T. Jiang, S. Wu, J. C. Ho, L. Wang, X. Chen and W. Lu, Small, 2015, 11, 936-942.

7 P. Norton, Opto-Electron. Rev., 2002, 10, 159-174.

8 A. Rogalski, J. Alloys Compd., 2004, 371, 53-57.

9 J. Wang, X. Chen, W. Hu, L. Wang, W. Lu, F. Xu, J. Zhao, Y. Shi and R. Ji, Appl. Phys. Lett., 2011, 99, 113508.

10 P. S. Wijewarnasuriya, Y. Chen, G. Brill, B. Zandi and N. K. Dhar, IEEE Trans. Electron Devices, 2010, 57, 782-787.

11 N. Liu, H. Tian, G. Schwartz, J. B. H. Tok, T. L. Ren and

Z. Bao, Nano Lett., 2014, 14, 3702-3708.

12 A. Rogalski, Rep. Prog. Phys., 2005, 68, 2267-2336.

13 V. Ryzhii and M. Ryzhii, Phys. Rev. B: Condens. Matter Mater. Phys., 2009, 79, 245311.

14 P. K. Saxena, Infrared Phys. Technol., 2011, 54, 25-33. 
15 P. K. Saxena, Def. Sci. J., 2017, 67, 141-148.

16 A. Rogalski and P. Martyniuk, Infrared Phys. Technol., 2006, 48, 39-52.

17 B. F. Levine, K. K. Choi, C. G. Bethea, J. Walker and R. J. Malik, Appl. Phys. Lett., 1987, 50, 1092-1094.

18 A. Asgari and S. Razi, Opt. Express, 2010, 18, 14604-14615. 19 A. Asgari, E. Ahmadi and M. Kalafi, Microelectron. J., 2009, 40, 104-107.

20 S. Bansal, K. Sharma, N. Gupta and A. K. Singh, in 2016 IEEE Uttar Pradesh Section International Conference on Electrical, Computer and Electronics Engineering, UPCON 2016, 2016, pp. 422-425.

21 M. Kopytko, A. Keblowski, W. Gawron, A. Kowalewski and A. Rogalski, IEEE Trans. Electron Devices, 2014, 61, 38033807.

22 N. D. Akhavan, G. A. Umana-membreno, R. Gu, J. Antoszewski and L. Faraone, IEEE Trans. Electron Devices, 2018, 65, 591-598.

23 P. K. Saxena and P. Chakrabarti, Infrared Phys. Technol., 2009, 52, 196-203.

24 A. D. D. Dwivedi, J. Appl. Phys., 2011, 110, 43101.

25 S. Bansal, K. Sharma, K. Soni, N. Gupta and A. K Singh, in 2017 Progress In Electromagnetics Research SymposiumSpring, PIERS, St Petersburg, Russia, 2017, pp. 981-983.

26 E. Bellotti and D. D'Orsogna, IEEE J. Quantum Electron., 2006, 42, 418-426.

27 A. Singh, A. K. Shukla and R. Pal, IEEE Trans. Electron Devices, 2017, 64, 1146-1152.

28 A. Piotrowski, P. Madejczyk, W. Gawron, K. Kłos, J. Pawluczyk, J. Rutkowski, J. Piotrowski and A. Rogalski, Infrared Phys. Technol., 2007, 49, 173-182.

29 M. Mohammadian and H. R. Saghai, Optik, 2015, 126, 11561160.

30 F. Xia, T. Mueller, Y. M. Lin, A. V. Garcia and P. Avouris, Nat. Nanotechnol., 2009, 4, 839-843.

31 B. Nie, J. G. Hu, L. B. Luo, C. Xie, L. H. Zeng, P. Lv, F. Z. Li, J. S. Jie, M. Feng, C. Y. Wu, Y. Q. Yu and S. H. Yu, Small, 2013, 9, 2872-2879.

32 S. Dhar, T. Majumder and S. P. Mondal, ACS Appl. Mater. Interfaces, 2016, 8, 31822-31831.

33 X. Wan, Y. Xu, H. Guo, K. Shehzad, A. Ali, Y. Liu, J. Yang, D. Dai, C.-T. Lin, L. Liu, H.-C. Cheng, F. Wang, X. Wang, H. Lu, W. Hu, X. Pi, Y. Dan, J. Luo, T. Hasan, X. Duan, X. Li, J. Xu, D. Yang, T. Ren and B. Yu, NPJ $2 D$ Mater. Appl., 2017, 1, 1-8.

34 D. Spirito, S. Kudera, V. Miseikis, C. Giansante, C. Coletti and R. Krahne, J. Phys. Chem. C, 2015, 119, 23859-23864.

35 Z. Gao, W. Jin, Y. Zhou, Y. Dai, B. Yu, C. Liu, W. Xu, Y. Li, H. Peng, Z. Liu and L. Dai, Nanoscale, 2013, 5, 5576-5581.

36 F. Lin, S. W. Chen, J. Meng, G. Tse, X. W. Fu, F. J. Xu, B. Shen, Z. M. Liao and D. P. Yu, Appl. Phys. Lett., 2014, 105, 73103.

37 X. Yu, Z. Dong, Y. Liu, T. Liu, J. Tao, Y. Zeng, J. K. W. Yang and Q. J. Wang, Nanoscale, 2016, 8, 327-332.

38 Z. Sun, Z. Liu, J. Li, G. A. Tai, S. P. Lau and F. Yan, Adv. Mater., 2012, 24, 5878-5883.
39 L. B. Luo, H. Hu, X.-H. Wang, R. Lu, Y.-F. Zou, Y.-Q. Yu and F.-X. Liang, J. Mater. Chem. C, 2015, 3, 4723-4728.

40 T. Mueller, F. Xia and P. Avouris, Nat. Photonics, 2010, 4, 297-301.

41 X. Gan, R. J. Shiue, Y. Gao, I. Meric, T. F. Heinz, K. Shepard, J. Hone, S. Assefa and D. Englund, Nat. Photonics, 2013, 7, 883-887.

42 A. Pospischil, M. Humer, M. M. Furchi, D. Bachmann, R. Guider, T. Fromherz and T. Mueller, Nat. Photonics, 2013, 7, 892-896.

43 V. Ryzhii, M. Ryzhii, V. Mitin and T. Otsuji, J. Appl. Phys., 2010, 107, 54512.

44 M. Ryzhii, T. Otsuji, V. Mitin and V. Ryzhii, Jpn. J. Appl. Phys., 2011, 50, 70117.

45 G. Konstantatos, M. Badioli, L. Gaudreau, J. Osmond, M. Bernechea, F. P. G. De Arquer, F. Gatti and F. H. L. Koppens, Nat. Nanotechnol., 2012, 7, 363-368.

46 M. Pykal, P. Jurečka, F. Karlický and M. Otyepka, Phys. Chem. Chem. Phys., 2016, 18, 6351-6372.

47 S. Zhao and J. Xue, Phys. Rev. B, 2012, 86, 1-10.

48 P. A. Denis, Chem. Phys. Lett., 2010, 492, 251-257.

49 W. Xu, Y. Gong, L. Liu, H. Qin and Y. Shi, Nanoscale Res. Lett., 2011, 6, 250.

50 S. Bae, H. Kim, Y. Lee, X. F. Xu, J. S. Park, Y. Zheng, J. Balakrishnan, T. Lei, H. R. Kim, Y. I. Song, Y. J. Kim, K. S. Kim, B. Ozyilmaz, J. H. Ahn, B. H. Hong and S. Iijima, Nat. Nanotechnol., 2010, 5, 574-578.

51 A. Kasry, M. A. Kuroda, G. J. Martyna, G. S. Tulevski and A. A. Bol, ACS Nano, 2010, 4, 3839-3844.

52 I. Khrapach, F. Withers, T. H. Bointon, D. K. Polyushkin, W. L. Barnes, S. Russo and M. F. Craciun, Adv. Mater., 2012, 24, 2844-2849.

53 Y. M. Shi, K. K. Kim, A. Reina, M. Hofmann, L. J. Li and J. Kong, ACS Nano, 2010, 4, 2689-2694.

54 K. K. Kim, A. Reina, Y. M. Shi, H. Park, L. J. Li, Y. H. Lee and J. Kong, Nanotechnology, 2010, 21, 285205.

55 V. C. Tung, L. M. Chen, M. J. Allen, J. K. Wassei, K. Nelson, R. B. Kaner and Y. Yang, Nano Lett., 2009, 9, 1949-1955.

56 J. K. Wassei, K. C. Cha, V. C. Tung, Y. Yang and R. B. Kaner, J. Mater. Chem., 2011, 21, 3391-3396.

57 X. Meng, S. Tongay, J. Kang, Z. Chen, F. Wu, S. S. Li, J. B. Xia, J. Li and J. Wu, Carbon, 2013, 57, 507-514.

58 L. Tai, D. Zhu, X. Liu, T. Yang, L. Wang, R. Wang, S. Jiang, Z. Chen, Z. Xu and X. Li, Nano-Micro Lett., 2018, 10, 1-9.

59 K. S. Novoselov, D. Jiang, F. Schedin, T. J. Booth, V. V. Khotkevich, S. V. Morozov and A. K. Geim, PNAS, 2005, 102, 10451-10453.

60 W. Jung, J. Park, T. Yoon, T. S. Kim, S. Kim and C. S. Han, Small, 2014, 10, 1704-1711.

61 C. J. Shearer, A. D. Slattery, A. J. Stapleton, J. G. Shapter and C. T. Gibson, Nanotechnology, 2016, 27, 125704.

62 R. Quhe, J. Ma, Z. Zeng, K. Tang, J. Zheng, Y. Wang, Z. Ni, L. Wang, Z. Gao, J. Shi and J. Lu, Sci. Rep., 2013, 3, 1-8.

63 F. Xia, D. B. Farmer, Y.-M. Lin and P. Avouris, Nano Lett., 2010, 10, 715-718.

64 A. Suhail, G. Pan, D. Jenkins and K. Islam, Carbon, 2018, 129, 520-526. 
65 F. H. L. Koppens, T. Mueller, P. Avouris, A. C. Ferrari, M. S. Vitiello and M. Polini, Nat. Nanotechnol., 2014, 9, 780-793.

66 J. Liu, Y. Yin, L. Yu, Y. Shi, D. Liang and D. Dai, Sci. Rep., 2017, 7, 1-7.

67 K. Patel and P. K. Tyagi, Carbon, 2017, 116, 744-752.

68 W. W. Anderson, Infrared Phys., 1980, 20, 363-372.

69 Y. Zhang, T. Liu, B. Meng, X. Li, G. Liang, X. Hu and Q. J. Wang, Nat. Commun., 2013, 4, 1811.

70 K. J. Tielrooij, J. C. W. Song, S. A. Jensen, A. Centeno, A. Pesquera, A. Zurutuza Elorza, M. Bonn, L. S. Levitov and F. H. L. Koppens, Nat. Phys., 2013, 9, 248-252.

71 Y. K. Lee, H. Choi, H. Lee, C. Lee, J. S. Choi, C. G. Choi, E. Hwang and J. Y. Park, Sci. Rep., 2016, 6, 1-9.

72 T. Plötzing, T. Winzer, E. Malic, D. Neumaier, A. Knorr and H. Kurz, Nano Lett., 2014, 14, 5371-5375.

73 J. C. Johannsen, S. Ulstrup, A. Crepaldi, F. Cilento, M. Zacchigna, J. A. Miwa, C. Cacho, R. T. Chapman, E. Springate, F. Fromm, C. Raidel, T. Seyller, P. D. C. King, F. Parmigiani, M. Grioni and P. Hofmann, Nano Lett., 2015, 15, 326-331.

74 F. Kadi, T. Winzer, A. Knorr and E. Malic, Sci. Rep., 2015, 5, $1-7$.

75 T. Winzer, A. Knorr and E. Malic, Nano Lett., 2010, 10, 48394843.

76 C. O. Kim, S. Kim, D. H. Shin, S. S. Kang, J. M. Kim, C. W. Jang, S. S. Joo, J. S. Lee, J. H. Kim, S. H. Choi and E. Hwang, Nat. Commun., 2014, 5, 3249.

77 M. G. Ancona, IEEE Trans. Electron Devices, 2010, 57, 681689.

78 A. D. D. Dwivedi and P. Chakrabarti, Opt. Quantum Electron., 2007, 39, 627-641.

79 ATLAS User's Manual Version 5.20.2.R, SILVACO International, Santa Clara, CA 95054, 2016.

80 M. H. Weiler, Semicond. Semimetals, 1981, 16, 119-191.

81 K. Patel and P. K. Tyagi, AIP Adv., 2015, 5, 077165.

82 P. K. Saxena and P. Chakrabarti, Optoelectron. Adv. Mater., Rapid Commun., 2008, 2, 140-147.

83 E. Ahmadi and A. Asgari, J. Appl. Phys., 2013, 113, 93106.

84 X. Li, M. Zhu, M. Du, Z. Lv, L. Zhang, Y. Li, Y. Yang, T. Yang, X. Li, K. Wang, H. Zhu and Y. Fang, Small, 2016, 12, 595601.

85 H. Selvi, N. Unsuree, E. Whittaker, M. Halsall, E. W. Hill, A. G. Thomas, P. Parkinson and T. Echtermeyer, Nanoscale, 2018, 10, 3399-3409.
86 H. L. Zhu, W. C. H. Choy, W. E. I. Sha and X. Ren, Adv. Opt. Mater., 2014, 2, 1082-1089.

87 J. Chu, Z. Mi and D. Tang, J. Appl. Phys., 1992, 71, 39553961.

88 J. Chu, B. Li, K. Liu and D. Tang, J. Appl. Phys., 1994, 75, 1234-1235.

89 K. Liu, J. H. Chu and D. Y. Tang, J. Appl. Phys., 1994, 75, 4176-4179.

90 A. Rogalski, Infrared Detectors, CRC Press, 2nd edn, 2010.

91 Y. Tian, B. Zhang, T. Zhan, H. Jiang and Y. Jin, IEEE Trans. Electron Devices, 2000, 47, 544-552.

92 P. Chakrabarti, A. Krier and A. F. Morgan, IEEE Trans. Electron Devices, 2003, 50, 2049-2058.

93 M. Casalino, U. Sassi, I. Goykhman, A. Eiden, E. Lidorikis, S. Milana, D. D. Fazio, F. Tomarchio, M. Iodice, G. Coppola and A. C. Ferrari, ACS Nano, 2017, 11, 1095510963.

94 M. Kopytko, A. Kebłowski, P. Madejczyk, P. Martyniuk, J. Piotrowski, W. Gawron, K. Grodecki, K. Jozwikowski and J. Rutkowski, J. Electron. Mater., 2017, 46, 6045-6055.

95 L. B. Luo, J. J. Chen, M. Z. Wang, H. Hu, C. Y. Wu, Q. Li, L. Wang, J. A. Huang and F. X. Liang, Adv. Funct. Mater., 2014, 24, 2794-2800.

96 X. Yu, Z. Dong, J. K. W. Yang and Q. J. Wang, Optica, 2016, 3, 979-984.

97 J. Shen, X. Liu, X. Song, X. Li, J. Wang, Q. Zhou, S. Luo, W. Feng, S. Lu, S. feng, X. Wei, C. Du, Y. Wang, H. Shi and D. Wei, Nanoscale, 2017, 9, 6020-6025.

98 J. Kim, S. Park, H. Jang, N. Koirala, J. B. Lee, U. J. Kim, H. S. Lee, Y. G. Roh, H. Lee, S. Sim, S. Cha, C. In, J. Park, J. Lee, M. Noh, J. Moon, M. Salehi, J. Sung, S. S. Chee, M. H. Ham, M. H. Jo, S. Oh, J. H. Ahn, S. W. Hwang, D. Kim and H. Choi, ACS Photonics, 2017, 4, 482-488.

99 X. An, F. Liu, Y. J. Jung and S. Kar, Nano Lett., 2013, 13, 909916.

100 L. B. Luo, Y. F. Zou, C. W. Ge, K. Zheng, D. D. Wang, R. Lu, T. F. Zhang, Y. Q. Yu and Z. Y. Guo, Adv. Opt. Mater., 2016, 4, 763-771.

101 Q. Gao and J. Guo, J. Appl. Phys., 2012, 112, 084316.

102 V. Ryzhii, M. Ryzhii, N. Ryabova, V. Mitin and T. Otsuji, Infrared Phys. Technol., 2011, 54, 302-305.

103 M. Moradinasab, M. Pourfath, M. Fathipour and H Kosina, IEEE Trans. Electron Devices, 2015, 62, 593-600. 